\title{
The Limits of Illustration: Animalia and Pharmacopeia from Guo Pu to Bencao Gangmu*
}

\author{
Roel Sterckx
}

\begin{abstract}
This paper examines the relationship between text and illustration in Chinese pharmacopeia in the bencao tradition by focusing on depictions of animals. It explores to what extent such illustrations served a practical—read medical or pharmaceutical — purpose. The first part of the paper discusses the contexts in which animal species have been depicted in traditional China leading up to the emergence of bencao literature. The second part analyses the use of illustrations in Bencao gangmu. The author questions whether such illustrations were aimed to reflect zoological, botanical, or pharmaceutical information not already present in the text and argues that, instead, their composition is best understood within the context of Ming visual culture, the print economy, and naturalist collectanea produced at the time.
\end{abstract}

\section{Keywords}

Bencao, Chinese medicine, Li Shizhen, medical illustration, Chinese pharmacopeia, animal representation, Chinese print culture

In The Eye of the Lynx, a study of the naturalist and founder of the Accademia dei Lincei Federico Cesi (1585-1630), David Freedberg draws attention to the perceived limitations associated with the use of pictures to classify natural objects in seventeenth-century Italy. One identified failure of illustrations was that they showed too much and left the naturalist caught between the desire to accurately picture everything and the desire for order. The more accurate pictures were the more detail they had to show. Yet, at the same time, the more biological detail they revealed the more they reflected the untidiness and disorder in nature and the less useful they were for taxonomic abstraction and classification. The ultimate tension for the Linceans, Freedberg notes, 'was

* I would like to thank the anonymous reviewers for their comments on an earlier draft of this paper. I am grateful to Geoffrey Lloyd, Georges Métailié, Teriyuki Kubo and Vivienne Lo for comments and suggestions, and to John Moffett of the Needham Research Institute for his help in locating materials. 
between the desire to record and describe everything (on the one hand), and the need to reduce and classify (on the other)'.

In China, about a decade after the birth of Cesi, the great naturalist Li Shizhen 李時珍 (1518-93) had just completed his landmark materia medica Bencao gangmu 本草綱目. Li Shizhen did not see his own work in print (in 1596) and had probably no hand in the preparation of illustrations that came to accompany the text and were compiled and drawn by his two sons, Li Jianzhong 李建中 and Li Jianyuan 李建元. ${ }^{2}$ By the seventeenth century, the inclusion of illustrations in pharmacopeia was by no means new. Bencao works were reported to have been illustrated as early as the Tang. Likewise animals, plants, rocks and other elements of nature had been depicted in various media since antiquity. Yet to the beholder of bencao illustrations the problem of representation sketched above by Freedberg and the inherent tension between detail and abstraction is equally relevant. What were the bencao illustrations meant to illustrate and, more importantly, wherein lay their value for medical and pharmaceutical purposes?

To be sure, the Linceans had analytical ambitions that went far beyond the degree of biological scrutiny apparent in any set of botanical or zoological illustrations known in China. And the bencao illustrators for their part operated in a different context, one that required them to design illustrations to complement an existing naturalist encyclopaedia anchored in a textual format inspired by lexicographical and commentarial conventions. These were predominantly focused on the explanation of graphs and texts rather than biological realities. A Chinese scholar's so-called 'naturalist' interest was to a great extent centred on the explanation of texts and nomenclature. The following anecdote recounted by Yan Zhitui 顏之推, sixth-century author of the Yanshi jia xun 顏氏家訓 (Family Instructions of Master Yan), illustrates such an attitude. It suggests that the learned in medieval China were not necessarily inclined to leave their study and experiment in the observation of nature, recall observations from the past, or record contemporary hearsay:

When I first read about the two-headed hui 螝 worm in Zhuangzi 莊子 of which the Han Feizi 韓非子says: 'Among the insects there is the hui, which has one body, two mouths, struggles for food, gnaw each other and so kill each other', I was at a loss, as I did not know the pronunciation of this character. I asked whomever I met, but no one could explain. According to the Erya 爾雅 and works of the same nature, the larvae of silkworms are called hui, but that is not

\footnotetext{
1 Freedberg 2003, p. 366.

2 For biographical sketches of Li Shizhen, see Needham 1986, pp. 308-12; Hubei sheng zhongyi yao yanjiuyuan (eds) 1984, pp. 1-16; Wang Jian 王剑 (ed.) 1996, pp. 1-37. On Li’s quest to get his work published, see also Nappi 2006, pp. 9-17.
} 
the two-headed creature with two mouths eager to harm each other. Then later on I noticed in the Gu jin $z i g u$ 古今字詁 (Dictionary of archaic and modern characters) that the character is the old form of hui 遗 [a venomous snake]. So the pending problem unsolved for years cleared up like dispersed fog. ${ }^{3}$

Yan Zhitui of course was hardly a naturalist or a physician in search of drugs. The latter might have been intrigued by the biological reality of this creature and perhaps even motivated to prove its existence outside a library. Yet Yan's attitude, according to which the mystery clears once a graph is traced to its etymological or lexical origins and its status in texts, was deeply engrained in writings dealing with the natural world as early as the Han. It is hard to imagine that this textual attitude suddenly gave way to observation and accurate representation in image by the time of Li Shizhen. ${ }^{4}$ If Yan Zhitui were asked to produce an illustration of his two-headed snake it is not unlikely that he would have to rely on imagination rather than observation. The same will apply to many of the illustrations surveyed in this essay.

With the exception of a few short passages in prefaces to bencao literature, next to nothing is known about the motivation behind the creation of their illustrations. Yet, this aporia of itself throws up an important question often overlooked in the treatment of illustrated materia medica or naturalist illustration at large in traditional China: namely, to what extent did such illustrations serve a practical—read medical or pharmaceutical—purpose at all? To develop this question, in what follows, I explore the contexts in which animal species have been depicted in traditional China leading up to and stretching into the period that saw the emergence of bencao illustrations. My account is by no means meant to be exhaustive. It merely serves to build up an aggregate picture of the types of pictorial practices that preceded the bencao illustrators, of the attitudes adopted towards representation in image, and of the sources that are significant stages along the way.

Generally, two styles of illustration can be distinguished across the transmitted corpus, albeit not always clearly. One could be referred to as the 'performative' or emblematic image, the other as the 'illustrative' or didactic image. The former are depictions that invite the observer or user to actively invoke the image as part of a performance, such as concentrating on an image as part of a ritual incantation, divination, or healing. By 'illustrative image', I mean images that complement an existing, mostly textual, narrative. Performative images are often accompanied by explanatory text captions, yet the

${ }^{3}$ Wang Liqi 王利器 (ed.), Yanshi jia xun jijie 顏氏家訓集解 (Beijing: Zhonghua, 1993), 3.226 ('Mian xue' 勉學).

${ }^{4}$ I have discussed this prevalence of textual exegesis in more detail in Sterckx 2002, pp. 2143; Sterckx 2005. 
latter usually remain subsidiary to the image. Illustrative images offer a type of annotation, supplement or commentary to the text. Their logical relationship to the text is usually generated through juxtaposition or implicit association and their absence does little to detract from the informative function of a text. My use of the term 'illustration' or 'picture' does not seek to distinguish pictorial media according to corresponding terms such as $t u$ 圖, hua 畫 or xiang 像, variously rendered as 'chart', 'diagram', 'image', 'plan', 'talisman', 'map', etc. I use these terms in a broad sense comprising any attempt at the pictorial representation of objects or, more specifically, creatures in the natural world. In short, we are concerned generally with modes in which information about the natural world was communicated visually. ${ }^{5}$

\section{Animal illustrations}

Little direct or indirect evidence survives for the pre-imperial and early imperial period of images that might have illustrated written texts or complemented performances such as songs or ritual liturgy. To be sure, pictorial evidence, including scenes that take the natural world as topic, is omnipresent in early China. Shang oracle bone-writing includes numerous pictographs representing animals; zoomorphic motifs pervade Shang and Zhou bronze vessel décor; and scenes depicting hunting expeditions, sacrificial slaughter, animal combats and games as well as various aspects of agricultural life abound in Han murals and on decorated ceramic bricks. ${ }^{6}$ References to officials recording landmarks and 'notable objects' (ming wu 名物) on maps suggest that maps

\footnotetext{
${ }^{5}$ In a recent collection of essays on $t u$ 圖, Francesca Bray proposes a generic definition for $t u$ : 'It was a specialist term denoting only those graphic images or layouts which encoded technical knowledge: $t u$ were templates for action. This concise definition seems to us to capture the essence of $t u$ across its many variations in pre-modern China. It elegantly resolves many of the confusions about apparently fuzzy boundaries between $t u$ and other graphic categories which have puzzled historians trying to place $t u$ as an intellectually coherent category. It highlights the fact that from the Chinese perspective $t u$ was not a stylistic but a functional category: $t u$ were instructive images conveying skilled, specialist knowledge. Tu offered spatial encodings (often but not necessarily two-dimensional) of factual information, structures, processes and relationships, translating temporal or intellectual sequences into purely spatial terms, and encrypting dynamic processes as static layouts.' See Bray et al. (eds) 2007, pp. 2-3. In addition to the applications of $t u$ discussed in this volume, see Lackner 1990; Innaccone 1996. Not discussed in this paper are European attempts to import zoological knowledge into China through means of illustration. Ferdinand Verbiest's contributions deserve a mention in this respect. See Iannaccone in Carletti et al. (eds) 1996.

${ }^{6}$ On the Shang origins of animal graphs, see Yang Xiaoneng 2000, pp. 90, 114; Li Haixia 李海霞 2002, pp. 208-10. On the Shang royal hunt, see Fiskesjö 2001. On the hunt, see Lewis 1990, pp. 150ff.; Sterckx 2004; and Sterckx, in press. On zoomorphic iconography, see Sterckx
} 
too could be illustrated. ${ }^{7}$ Likewise, murals have been preserved that illustrate textual narratives, often exemplifying famous episodes from the classics. The most notable examples are preserved in the shrines of the Wuliang 武梁 family (2nd century CE; Jinxiang county, Shandong). ${ }^{8}$

Most agricultural or natural scenes in Warring States and Han murals appear as decorative statements of their own right; some form part of a larger pictorial narrative or are intended to illustrate an existing textual narrative. Zoomorphic imagery appears, or was reported to appear, predominantly on artefacts, buildings, and implements related to ritual culture, most notably, funerary art. Reconstructing the exact context and meaning behind many of these motifs remains problematic. ${ }^{9}$ A hybrid creature on a bronze is likely to contain iconographic meaning that testifies to religious, mythological or cosmological concepts (now lost to us in many cases). A hunting scene in a tomb or palace mural depicting a successful real or imaginary campaign might serve to glorify the reputation of its owner or occupant.

While relatively little direct pictorial evidence has survived, several passages in Warring States and Han texts preserve important information on the kinds of attitudes that were adopted vis-à-vis pictorial representation. The first reference to the use of apotropaic illustrations occurs in the Zuozhuan 左傳, in the story of $\mathrm{Yu}$ 禹 the Great's casting of nine talismanic tripods:

Anciently, when the Xia (territory) was marked by virtue, the distant regions made pictorial (representations) of the creatures (in their region), and tributes of metal (were sought from) the Nine Herdsmen. Tripods were cast with those creatures represented on them. All creatures (being thus revealed), (instructions were given) of preparations (to be made), so that the people would know these spirits and evils. Therefore when people entered rivers, marshes, hills and forests, they would not meet or follow them; and the chimei 魑魅 or wangliang 罔兩 demons would not meet with them. Thus they could harmonize high and low, and enjoy the favours of heaven. ${ }^{10}$

Elsewhere I have discussed this passage as an early example of cosmographic collection and linked it to the image of herding and shepherding as a meta-

in Wang (ed.), in press. Han murals with agricultural and hunting scenes are collated in Xia Henglian 夏亨廉 et al. (eds) 1996.

7 See, for example, Sun Yirang 孫詣讓 (ed.) Zhouli zhengyi 周禮正義 (Beijing: Zhonghua, 1987), 18.689 ('Da situ'). See further Liu Keming 刘克明 2003, pp. 84-92.

${ }^{8}$ For the main studies, see Wu Hung 1989; Powers 1991; Liu et al. (eds) 2005.

9 On the interpretation of zoomorphic motifs, see Wang et al. 2006.

${ }^{10}$ Yang Bojun 楊伯峻, Chunqiu Zuozhuan zhu 春秋左傳注 (Beijing: Zhonghua, 1995), pp. 669-71 (Lord Xuan, year 3). See further Shuowen jiezi 說文解字, Shanghai: Shanghai guji, 1983, 7A.35b; Shiji 史記, Beijing: Zhonghua, 40.1700; and Liu Pansui 劉盼逐 (ed.), Lunheng jiaoshi 論衡校釋 (Beijing: Zhonghua, 1990), 26.375-76. 
phor for representing and controlling the world. ${ }^{11}$ We are not told here how the images of the unpropitious creatures were cast on to the vessels. It is also not known whether they were accompanied by inscriptions that identified their name or shape. But this brief passage set a precedent for the image of the tripod (ding 鼎) as a medium to depict the names and shapes of demonic and strange creatures. This is, for instance, reflected in titles of later treatises that were purported to be repositories of the strange such as a text known as the Jiu ding ji 九鼎記 (Record of the Nine Tripods) or another piece quoted as the 'Xia ding zhi' 夏鼎志 (Treatise on the Xia Tripods). ${ }^{12}$ Although spanning too much of a time-gap to allow us to draw parallels with any confidence, the idea of images being solicited by a central authority to be represented in a lasting medium (bronze in this case) and, following an 'editorial' operation, re-issued as a guide to the unknown, recalls later imperially sponsored edicts ordering illustrations of materia medica to be submitted to editorial teams.

Several passages in Warring States texts discuss the perceived limits or benefits associated with pictorial representation. A story in the Han Feizi has a painter explain to his king that it is harder to draw dogs and horses than to depict ghosts and demons. A familiarity with domestic animals, he explains, leads to a more accurate representation. By contrast, the shapelessness of spirits leaves too much room for artistic fantasy. ${ }^{13}$ In addition to criticizing the limited remit of pictorial representation, this anecdote contains an implicit warning: explaining unfamiliar creatures away as ghosts and demons deludes the observer of such images, 'imagi-nation' is the incapability to differentiate representations from actual reality. The idea is further illustrated in the story of $\mathrm{Zi} \mathrm{Gao}$ 子高 (fl. ca. $523 \mathrm{BCE}$ ), who was so fond of dragons that he had his lodgings decorated with carvings of dragons. Until one day a real dragon descended in front of his residence and he had to run away in fear. His fashioning of dragon images had prompted the arrival of a real dragon. ${ }^{14}$

11 Sterckx 2002, pp. 118-20.

12 Jiu ding ji' is quoted in Baopuzi neipian jiaoshi 抱朴子内篇校釋, Beijing: Zhonghua, 1996, 17.308, but is also associated with a Tang authorship. See Jiu Tangshu 舊唐書, Beijing: Zhonghua, 1975, 189B.4979; and as quoted in Taiping yulan 太平御覽 (Sibu congkan ed.), 883.7a, and Tian zhong ji 天中記 (Siku quanshu ed.), 55.55a. For the Xia ding zhi, see Jinshu 晉書, Beijing: Zhonghua, 1947, 28.853; Songshu 宋書, Beijing: Zhonghua, 1974, 31.923; Sou shen ji 搜神記, Shanghai: Shangwu yinshuguan, 1957, 12.90; Tang Kaiyuan zhan jing 唐開元占經 (Siku quanshu ed.), 119.4a.

${ }^{13}$ Chen Qiyou 陳奇猷 (ed.), Han Feizi jishi 韓非子集釋 (Gaoxiong: Fuwen, 1991), 11.633 ('Wai chu shuo zuo shang'). See also Liu Wendian 劉文典 (ed.), Huainanzi honglie jijie 淮南子 鴻烈集解 (Taipei: Wenshizhe, 1992), 13.432 ('Fan lun').

${ }^{14}$ Creel 1974, fragment 15, p. 363. See also Zhao Zhongyi 趙仲邑 (ed.), Xinxu xiang zhu 新序詳註 (Beijing: Zhonghua, 1997), 5.173 ('Za shi'); Lunheng jiaoshi, 47.698-99 ('Luan long'); Hou Hanshu 後漢書, Beijing: Zhonghua 1965, 30B.1082 note 3; 52.1719 note 2. 
In another story, the Han Feizi links the concept of imagination to a lack of familiarity or visualization in a pun on the character xiang 象, meaning both 'elephant' and 'image'. ${ }^{15}$ The passage presents the sage as an agent able to interpret images as a referent to a reality not visible to the common eye. The sage is also said to be able to represent what is absent in its bodily or physical form. Similar debates on the nature of visual representation continued into the Eastern Han. Zhang Heng 張衡 (78-139 CE) for instance is on record commenting as follows on the Han Feizi anecdote on why artisans prefer to depict ghosts instead of real animals: 'Truly, it is because substantial entities are difficult to represent in form, while empty counterfeits are inexhaustible' (cheng yi shishi nan xing er xuwei bu qiong ye 誠以實事難形而虛鶏不窮也). ${ }^{16}$

Turning to presently transmitted illustrations, a piece that deserves a mention is the famous Chu silk manuscript, recovered by tomb robbers in 1942 in Zidanku 子彈庫, Changsha (Hunan), dating to $c a .300$ BCE and now kept in the Arthur M. Sackler Gallery in Washington DC. The manuscript (ca. $38 \times$ 47 centimetres) was first studied in the West by Noel Barnard in the 1970s. It is designed in the shape of a divination board and contains 12 peripheral hybrid creatures that possibly represent the deities corresponding to each of the 12 calendar months described in the text. ${ }^{17}$ The link between the creatures and the text itself is debated and, although the figures carry three-character labels of their name, it is hard to establish whether its author(s) intended to design the piece as an illustrated text or whether it originated as a set of

${ }^{15}$ Han Feizi jishi, 6.368 ('Jie Lao').

${ }^{16}$ Hou Hanshu, 59.1912. Zhang here likens those who rely on prognostication charts (instead of empirical astronomical observation) to painters preferring to draw ghosts and demons. Several occurrences are recorded in which murals, pictures and portraits were used didactically. One instance records the ageing Han Wudi 漢武帝 intimating to his Marshal of State, Huo Guang 霍光, that he should supervise the named infant successor to the throne as regent. Wudi made his will clear by commissioning a wall mural showing the Duke of Zhou carrying the infant King Cheng 成on his back. See Hanshu 漢書, Beijing: Zhonghua, 1962, 68.2932. A passage in the Kongzi jiayu 孔子家語 has Confucius contemplating a similar scene at the Bright Hall (Ming tang 明堂). See Kongzi jiayu (Sibu beiyao ed.), 3.1b-2a ('Guan Zhou’ 觀周). In 178 CE, Cai Yong 蔡匘 (133-92 CE) painted a mural of Confucius and his 72 disciples on the wall of the imperial academy to urge on its students to study. See Hou Hanshu, 60B.1998.

${ }_{17}$ For a translation of the accompanying text, see Barnard 1973, pp. 175-203. In volume three of this series, Barnard discusses the relevance of the Shanhaijing 山海經 and other texts for the explanation of the 12 peripheral figures. See also Li Xueqin 李学勤 1994. The cosmic board theory is set out in Li Ling 李零 2000, pp. 89-176, 178-96. A brief summary and translation by Li Ling and Constance Cook also appears in Major and Cook (eds) 1999, pp. 171-6. Mark Lewis discusses its spatial layout as a precursor of the 'Bright Hall' (Ming tang 明堂) model in Lewis 2006, pp. 261-2. 
illustrations annotated with a text. ${ }^{18}$ It is noteworthy, however, that in what remains of the text captions, no direct reference is made to the shape and colour of the drawings. This suggests that their iconography (unattested elsewhere) was part of a stock of generic imagery known to people at the time or, alternatively, that the drawings were a product of the imagination of the illustrator(s) at the time. What is clear is that the texts are describing the properties of the deities represented but it remains uncertain whether the text should be seen as primary over the image or as an explanatory commentary on the image.

Moving to early imperial times, the Mawangdui 馬王堆 finds represent an important stage for the study of illustrated manuscripts in the early Han. ${ }^{19}$ Noteworthy for our purpose is the silk painting referred to as Bibing tu 避兵圖 (Repel weapon chart) from tomb no. 3 and the illustrations on a silk astronomical chart (Tianwen qixiang za zhan 天文氣象雜占; 'Miscellaneous astrological and astronomical divinations'). The 'Repel weapon chart'—which some scholars prefer to refer to as the 'Taiyi jiangxing tu' 太一 將行圖 (Drawing of the Procession before the Departure of Taiyi) ${ }^{20}$ — depicts the high god Taiyi (Grand One) flanked by Lord Rain and Lord Thunder to his right and left respectively. Below Taiyi are four armed figures holding a knife, sword, bow and a spear. A hybrid creature rises toward Taiyi from between two dragons at the bottom. The armed figures together with the text in the right margin have led some scholars to conclude that this piece was made in support of a military campaign. ${ }^{21}$ Others have focused on Taiyi's left arm, underneath which is written the character she 社 (earth altar/soil spirit), which could indicate that the illustration was used to worship a particular deity, perhaps in a prayer for rain. Regardless of its exact function, it is clear that this illustration was meant to be visible and hence likely to be used during a ritual performance of some kind. ${ }^{22}$ The silk scroll designated 'Tianwen qixiang za zhan' illustrates celestial phenomena such as clouds and halos and figures in the

${ }^{18}$ Hayashi Minao 林已奈夫 has suggested that the figures represent Chu shamans. See Hayashi Minao 1971. Vera Dorofeeva-Lichtmann argues that 'the pictures of spirits are also designed in such a way -with heads adjacent to the centre-that their examination, similar to reading the related textual passages, also requires rotating the manuscript or a circular movement by its 'user". See Dorofeeva-Lichtmann 2007, p. 245.

19 All $t u$ 'diagram' manuscripts among the Mawangdui finds are conveniently surveyed in Lai Guolong 2003, pp. 44-8.

20 See Chen Songchang 陳松長 1993.

${ }^{21}$ See Harper 1999, 870-1. The text passage usually quoted in support of this interpretation is at Shiji, 28.1395. It describes the making of a 'spirit banner' (ling q $i$ 靈旗) prior to a campaign against the Southern Yue.

22 See Zhou Shirong 周世榮 1990; Li Ling 1991. 
shape of animals, including a well-preserved creature in the shape of a dragonhorse. The illustrations are accompanied by texts naming the portents or the event(s) they predict. The relationship between the illustrations and the accompanying divination texts continues to be debated. ${ }^{23}$ It is plausible that text and illustration came together at different stages and were compiled from different originals by several scribes. ${ }^{24}$

Illustrated texts such as the Chu silk manuscript and the Mawangdui charts discussed above are twentieth-century finds that add a small piece to our very fragmentary understanding of the use of illustrations in early China. And while they were evidently not available to bencao illustrators, the creatures they depict appear cognate to the types of animalia described in a frequently adduced source in bencao literature and commentary, namely the Shanhaijing 山海經 (Classic of Mountains and Waters). This text has variously been described as a manual on prodigies, a geographical gazetteer or explanatory notes on illustrations or maps. ${ }^{25}$ While the oldest extant illustrations that were printed independently or accompany text editions of the Shanhaijing are of Ming and Qing date, illustrations existed possibly as early as the third century CE. ${ }^{26}$ Guo Pu 郭璞 (276-324 CE) mentions illustrations in his commentary and wrote appraisals of them in a work known as the Shanhaijing tu zan 山海經圖讚 (Appraising the Illustrations to the Shanhaijing), preserved in both the Daozang and Sibu beiyao editions. The poet Tao Yuanming 陶淵明

${ }^{23}$ Harper 1999 , p. 844. In a recent article, Donald Harper, who prefers to translate qixiang as 'meteoromantic', emphasises that the drawings on this manuscript need not reflect empirical observation. He argues that they 'render phenomena using designs that, once established, predisposed the ancient observer to correlate what was seen in nature with these drawings from the initial moment of observation; that is, the drawings had a determining influence on the elite's perception of nature'. In other words, the drawings here encourage people 'to see what they are looking for' and the Han reader was thus invited to 'match omen statements not recorded in writing on the manuscript with the categories represented by the drawings'. See Harper 2007, pp. 169-89 (quotes pp. 172, 174).

${ }_{24}$ The theory that the texts were added after the production of the illustrations is set out in detail in Chen Songchang 2006. Chen concludes that the chart was copied in its current form around 196 BCE or slightly afterwards. Another case in support of a text allegedly derived from graffiti has been made by Wang Yi 王逸 (2nd century CE) who claimed that Qu Yuan 屈原 (4th century BCE) wrote down the 'Tian wen' 天問 (Heavenly Questions) on murals in ancestral temples of former kings and minsters of Chu. While not implausible, the content of the Heavenly Questions, as David Hawkes notes, appears rather abstract to be linked to a series of pictures. See Tang Bingzheng 湯炳正 et al. (ed.), Chuci jin zhu 楚辭今注 (Shanghai: Shanghai guji 1996), 80-1; Hawkes 1985, pp. 123-4.

25 For a recent, highly speculative 'zoological' reading of the Shanhaijing, see Guo Fu 郭郛 2004 .

${ }^{26}$ See Fracasso 1988; Fracasso 1993. Guo Pu’s commentarial oeuvre is surveyed in Fracasso 1996. 
(365-427 CE) claims to have derived poetic inspiration from glancing at Shanhaijing illustrations. ${ }^{27}$ Several other titles of works, now lost to us, refer to Shanhaijing illustrations. So while it is impossible to establish whether Shanhaijing illustrations circulated in pre-Han times, continuous reference to accompanying $t u$ in the commentarial tradition suggests that they existed very early on. The oldest extant woodblock illustrations, by an unknown artist, are reproduced in a 1597 reprint of Wang Chongqing's 王崇慶 Shanhaijing shiyi 山海經釋義 (1537). ${ }^{28}$

Two other illustrated works are attributed to Guo Pu. According to the bibliographical treatise of the Suishu 隋書, the Erya tu 爾雅圖 (Illustrated Erya) consisted of ten scrolls. It is mentioned together with Erya tu zan 讚 (Appraised Illustrations to the Erya) in two scrolls. The originals of both works were lost by Sui times. ${ }^{29}$ Guo Pu's practice of commenting on illustrations survived, at least nominally, in other works in the 'tu zan' 圖讚 (Appraised illustrations) tradition. One work worth mentioning is Yang Shen's 楊慎 (1488-1559) Yi yu tu zan 異魚圖讚 (Appraised illustrations of strange fish), preserved in four scrolls in most transmitted editions but unfortunately without the illustrations. ${ }^{30}$

Despite Guo Pu's appraisals of now lost illustrations to the imaginary bestiary of the Shanhaijing, only a few examples of animal images illustrating charts or texts survive from the medieval period. ${ }^{31}$ One notably rich source are the

27 See Lu Qinli 逤欽立 (ed.) Tao Yuanming ji 陶淵明集 (Beijing: Zhonghua, 1979), 4.133 ('Du Shanhaijing shi-san shou’ 讀山海經十三首).

${ }^{28}$ It is, as Vera Dorofeeva-Lichtmann has argued, very unlikely for technical reasons that illustrations of the type referred to by Guo Pu were part of the original text(s) circulated on bamboo slips. Incorporating illustrations into the text may only have been technically possible for versions written on silk. Guo Pu's 'Tu zan' therefore more likely existed as a reflective appendix to the text and the illustrations might have circulated separately from the text. See Dorofeeva-Lichtmann 2007.

${ }^{29}$ See Suishu (Beijing: Zhonghua, 1973), 32.937. The relationship between these two works and another work entitled Erya yin $t u$ 爾雅音圖, printed in 1801 and based on illustrations allegedly copied in the Song, is dubious. For an art historical perspective, see Wang Hongbin 王鸿宾 2006.

${ }_{30}$ 'Yi yu tu zan' survives in several editions (and is included in the Siku quanshu and Congshu jicheng). Commentaries and supplements to the text include a Yi yu tu zan jian 異魚圖讚箋 and a Yi yu tu zan bu 異魚圖讚補 by Hu Shi-an 胡世安 (d. 1663). The latter is also known as the author of a short work (referred to as Run ji 閏集), once described by Alexander Wylie (181587) as a 'small brochure on piscatorial monstrosities'. See Wylie 1901, p. 154. For a biographical sketch and survey of Yang Shen's literary work, see Cigliano 1996.

${ }^{31}$ One text worth mentioning but highly problematic in its dating is the extant version of the Huangdi hamajing 黃帝蝦蟆經 (The Yellow Emperor's Toad Canon) which contains illustrations of the three-legged-bird-in-the-sun and a toad-and-hare-in-the-moon. It only survives in an 1823 Japanese woodblock edition. Vivienne Lo has argued recently that its medical ideas might situate it as far back as the early Tang. See Lo 2001. 
manuscripts related to divination from Dunhuang. These include the sixthcentury illustrated demonography entitled Baize jingguai tu 白澤精怪圖 (Illustrations of Baize, Sprites and Oddities) (P2682 recto; S6261) which contains 19 images of portentous animals spirits and creatures with brief text captions of two to four columns preceding them. They include variously coloured roosters said to call out the names of household members at night, a hybrid bird with a human head, serpents, a mouse climbing a tree trunk, a dragon and a chicken. Each is meant to be an image of the portents and demons described in the captions. Another fragment (S6261) of the same text as P2682 recto preserves six illustrations including a rabbit and a dog emerging from the soil. Possibly of late Han or early medieval date, it is clear that such illustrated guidebooks were popular by Tang times when various versions of a text carrying a similar title circulated. ${ }^{32}$

Other manuscripts in the Dunhuang corpus are a rich repository of animal illustrations. P2683 contains 23 colour images of animal omens. The text names 42 fabulous animals (nineteen illustrations are missing) divided in three categories: tortoise, dragon, and a phoenix-like bird. The captions describe the shape of the creature, the circumstances of its appearance, and explain the omen related to its appearance. ${ }^{33}$ Most illustrations occur in so-called rui tu 瑞圖 (Illustrations of Auspicious Omens). S2404 contains an image of one of the cyclical animals (a monkey). The cyclical animals are further found on P4058B verso, S612 recto and S-P6 recto. Crows are depicted in a manuscript that deals with the mantic art of interpreting birdcalls (P3479 recto). Dragons appear in several other manuscripts not mentioned above (P3594 recto, P3602 verso). The image of a bird occurs in a hemerological text used to predict a person's fate according to their date of birth in the animal zodiac (P4881).

\section{Bencao illustrations}

Depending on the label one wishes to attach to the Shanhaijing and its reported illustrations, it is not until the Tang period that we find references to illustrated pharmacopoeia. They were part of a work in the main bencao tradition. ${ }^{34}$ The oldest known illustrated bencao work is commonly referred to as the Tang bencao 唐本草 or Xin xiu bencao 新修本草 and was compiled by an

32 For an excellent survey of the contents of these manuscripts, see Catherine Despeux's entry in Kalinowski 2003, pp. 436-43, 467.

33 Kalinowski 2003, pp. 458-61.

34 The most notable scholars to have worked on the bencao tradition include Ma Jixing 馬繼興, Joseph Needham, Paul Unschuld, and Nathan Sivin. For an overview of bencao literature, 
editorial committee including Su Jing 蘇敬 (ca. 657 CE), Li Ji 李勣 and others. It was published in 659 and is the first work to include drug illustrations ( yao $t u$ 葯圖, in 25 chapters) and commentaries thereon ( yao jing 葯經, in 7 chapters). Its illustrations are now lost but we know from the preface that its publication followed an empire-wide decree two years earlier inviting people to collect and submit locally known drugs to the editors. These were then drawn, allegedly, 'in rich colours'. The preface further reveals that part of the motivation behind this grand government-sponsored quest for materia medica was the knowledge that animals and plants showed regional characteristics that were relevant to their pharmaceutical use and hence required to be represented accurately. ${ }^{35}$ How this might have been reflected in the actual illustrations remains unknown, although some illustrations in later bencao do make attempts to sketch landscape and vegetation as background to the creatures, possibly giving some account of regional variation (Figure 1).

A more significant moment in the history of bencao illustrations occurred in the Northern Song, when Su Song 蘇頌 (ca. 1020-1101) put together illustrations into what became known as the Tu jing bencao 圖經本草 (Illustrated Guide through Bencao, completed in 1062). This work, also known as Bencao tu jing, contained over 900 illustrations and, according to its preface, was prepared as a replacement for the lost illustrations in Xin xiu bencao. According to the preface, it was completed following an imperial order. In the same preface, the scholar-physician Zhang Yuxi 掌禹錫 (992-1068) insists on the universal and encyclopaedic ambition of the work. It not only had to sort out 'the thousands of different drug specimens that have now been drawn in illustrations in the empire' but also to include information beyond what medical practitioners had heard and seen, including explanations that relied on previously existing commentaries and outside works ranging from historical works to novels. ${ }^{36}$ As is suggested by its title-which Nathan Sivin translates 'Illustrated pharmaceutical natural history' ${ }^{\prime}$ — the use of illustrations here appears to be central and they are presented as a genuine medium through which pharmaceutical knowledge can be transmitted. Illustrations are judged to be useful on account that they can help physicians distinguish genuinely useful plants and animals from others:

see Needham 1986, pp. 220-38. The best Western language study of the bencao corpus and its prefaces to date is Unschuld 1986, to which I am much indebted in this section.

35 See Unschuld 1986 , pp. 45-50, which includes a translation of the preface. See also Unschuld 2000, p. 104.

36 Preface, as translated in Unschuld 1986, pp. 65-6.

37 See Needham 1986, p. 56. 


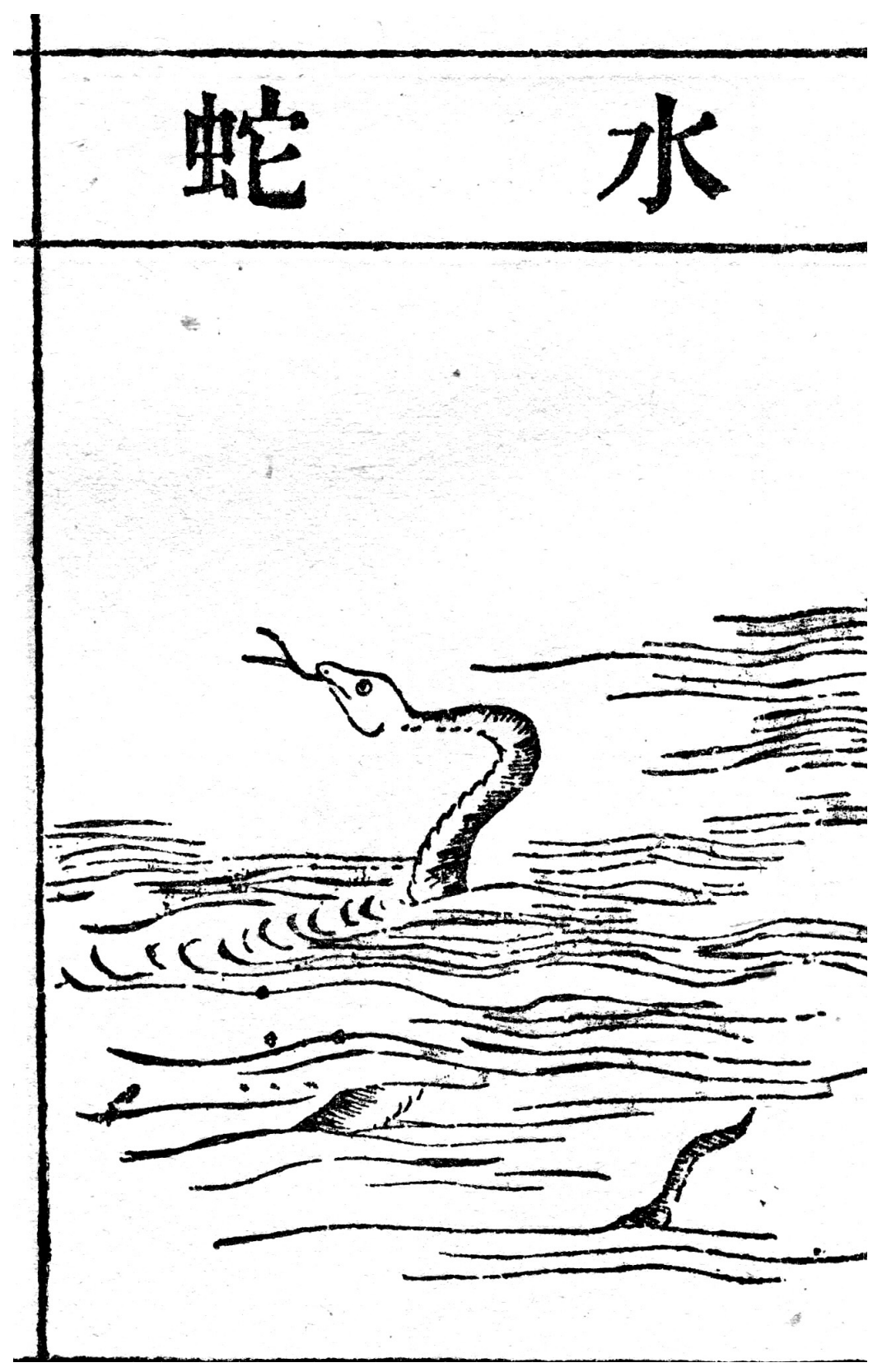

Fig. 1a 


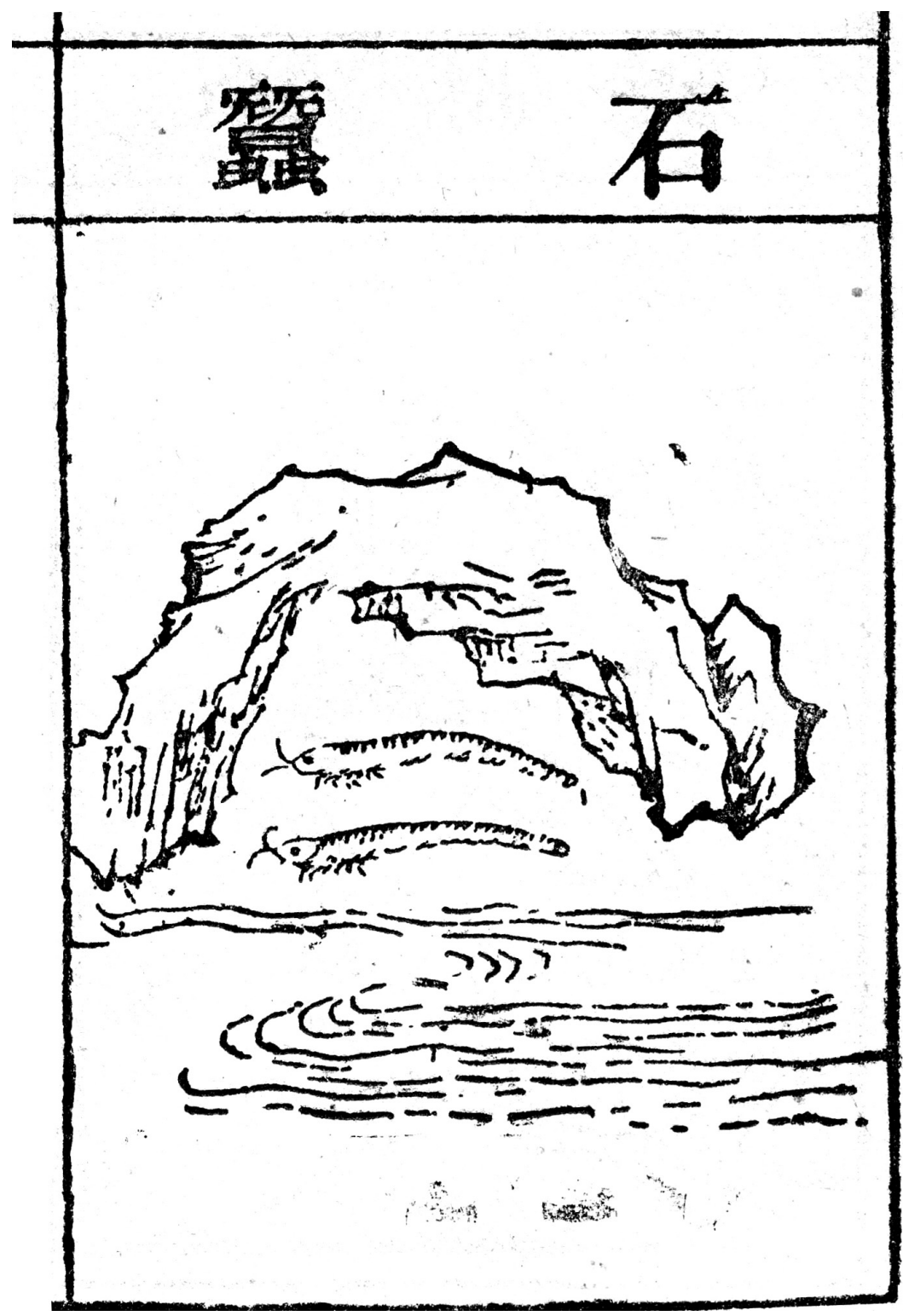

Fig. $1 \mathrm{~b}$

Fig. 1. Bencao gangmu (1885)

a) Fresh-water snake (shui she 水蛇) and b) caddis fly (shi can 石䖯).

Source: Bencao gangmu (Shanghai: Shangwu yinshuguan, 1933), vol. 1, 30, 45. 
Illustrations are used to represent the appearance and colour [of the drugs], the jing [commentaries] serve to explain their similarities and differences (tu yi zai qi xingse, jing yi shi qi tongyi 圖以載其形色, 經以釋其同異). ${ }^{38}$

Yet implicit in this statement also is an admission that without explanatory notes, the use of illustrations is reduced to approximate recognition. The imperial decree issued in 1058 and petitioned by the authors in preparation for the work makes the same point:

Shape, colour, and size of roots, stalks, shoots, leaves, blossoms, and fruits, as well as worms, fish, birds, quadrupeds, precious stones, and minerals, if suitable for pharmaceutical use, should be drawn in illustration one by one, accompanied by an explanatory comment, describing, for every single object, the time of blooming [etc.].... The evidence [gathered in this manner] is to serve as a basis for the creation of bencao illustrations. In addition commentaries are to be written for the illustrations. ${ }^{39}$

The decree continues by stating that these annotated illustrations are to be circulated with the bencao compiled during the current governmental period. Illustrations here do not appear to be valued as an independent means for the transmission of knowledge since they are expected to be accompanied by explanatory notes from the start. Likewise the involvement of an editorial team at the centre of its compilation suggests that the illustrations were standardized models derived from a copious number of drawings submitted. In other words, in the realm of the visual, as in the world of textual exegesis, standardisation is at work similar to the processes associated with the compilation of etymological lexicons and glossaries of regional dialects or calligraphies. The pharmacist appears to rely as much on methodologies inspired by textual exegesis as on practitioner's experience: ordering and rectifying the wide array of medicinal products gathered from all over the empire; juxtaposing competing explanations on the workings of the drugs; glossing together identical plants and animals that live in different regions; sorting out nomenclature, etc. In short, the most cogent steps of data-gathering appear to consist of examining and comparing the occurrence of drugs in texts from the past; in the case of Su Song and his team, nearly 200 sources. $^{40}$

The original of the Tu jing bencao is lost and nothing is known with certainty of its original illustrations. Its text and illustrations, however, are preserved in fragmentary form in the Daguan 大觀 edition of Tang Shenwei's

38 Shang Zhijun 佁志钧 (ed.), Bencao tujing 本草圖經 (Hefei: Anhui kexue jishu chubanshe, 1994), p. 1.

39 Unschuld 1986, p. 67, relying on the text in Okashini Tameto's 罔西爲人 Song yiqian yiji $k a o$ 宋以前醫籍考 (1969).

40 See Gao Guangzhen 高光震 1991. 
唐慎微 Zhenglei bencao 證類本草 (Categorized Pharmacopoeia, collated late 11 th-12th century) as well as the Bencao gangmu. In a recent reconstructed version of the fragments it contains 814 entries, 642 of which have illustrations appended to them (Figure 2) ${ }^{41}$ Assuming then that some of the original illustrations collated by $\mathrm{Su}$ Song were reproduced in some form or another in the oldest completely preserved bencao, the Daguan bencao of $1108 \mathrm{CE}$, the latter should be the source that holds the oldest presently transmitted animal illustrations in pharmaceutical texts. But, as Paul Unschuld points out, this is also where illustration stagnates since little innovation seems to have followed: 'In the subsequent illustrated bencao works of the Song period, there seems to have been no urge to prepare new illustrations of the plants, animals and minerals for each new edition of the materia medica-unless they were listed for the first time. ${ }^{32}$ One probably must allow for the fact that illustrations reproduced in printed works had to conform to some extent to the creative conventions of the schematic woodblock print. Unschuld suggests that they were created primarily for didactic purposes: 'plants, plant parts, minerals, and the instruments used for their preparation, and animal and human medicinal drugs are still frequently and recognisably depicted'. ${ }^{43}$ Speaking of botanical illustration in Bencao gangmu, Métailié and Haudricourt likewise speculate that the schematic nature of the illustrations might be didactic: allowing someone who already knows the plants to retrieve them easily. However, they also point out that it remains difficult to reconcile detailed emphasis on certain morphological features on the one hand, with the overall poor quality of the illustrations on the other. ${ }^{44}$ Yet while they may have been created for instructive purposes, one might also question the didactic efficiency of these illustrations. How valid could they have been to a practitioner operating in the field, centuries after the original creation of the images he is confronted with and, most likely, far removed from the social and regional environment in which those drugs were initially collected, identified and reported? Was it the case that, once a plant or animal drug had been fixed in image, it was simply

41 Shang Zhijun (ed.) 1994. The illustrated animal entries in this work occupy chapters thirteen (qin shou 禽獸), fourteen and fifteen (chong yu 蟲魚). Chapter fourteen starts off with an entry on dragon bones (long gu 龍骨).

${ }^{42}$ Unschuld 1986, p. 67. In his introduction, Unschuld underlines that 'the nature of illustration and the structural patterns discernable in the herbals' serve as a caution not to assume steady linear progress from 'speculation to observation, from belief to truth' (p. 7).

43 Unschuld 2000, p. 104.

44 Métailié and Haudricourt 1994, pp. 386-96. Discussing the picture of a wutong 梧桐 tree in Bencao gangmu, Métailié speculates: 'It seems to me that once the text is memorised and associated with the picture, the picture can serve to tickle the memory even if it is not a true representation of the real wutong tree'. See in Métailié 2007, p. 493. 


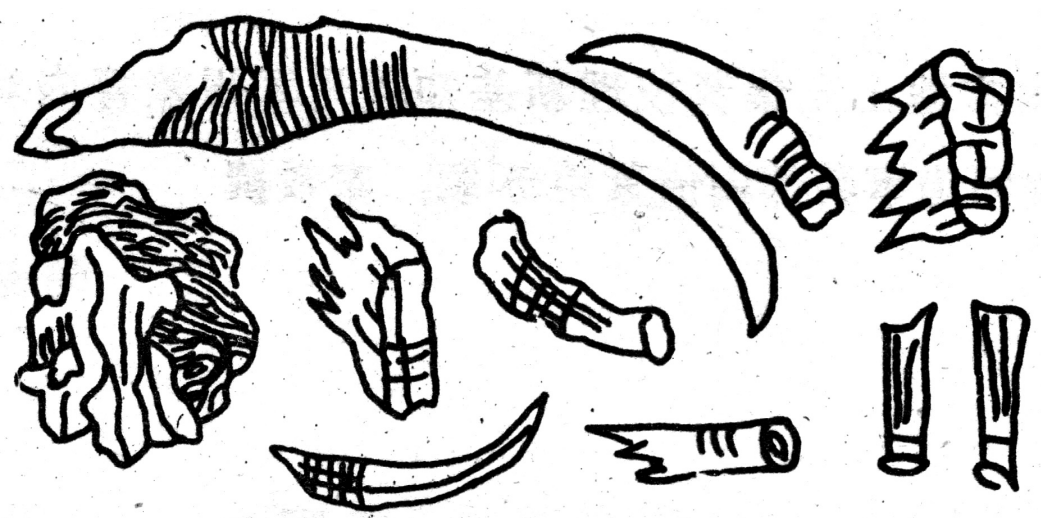

Fig. 2a

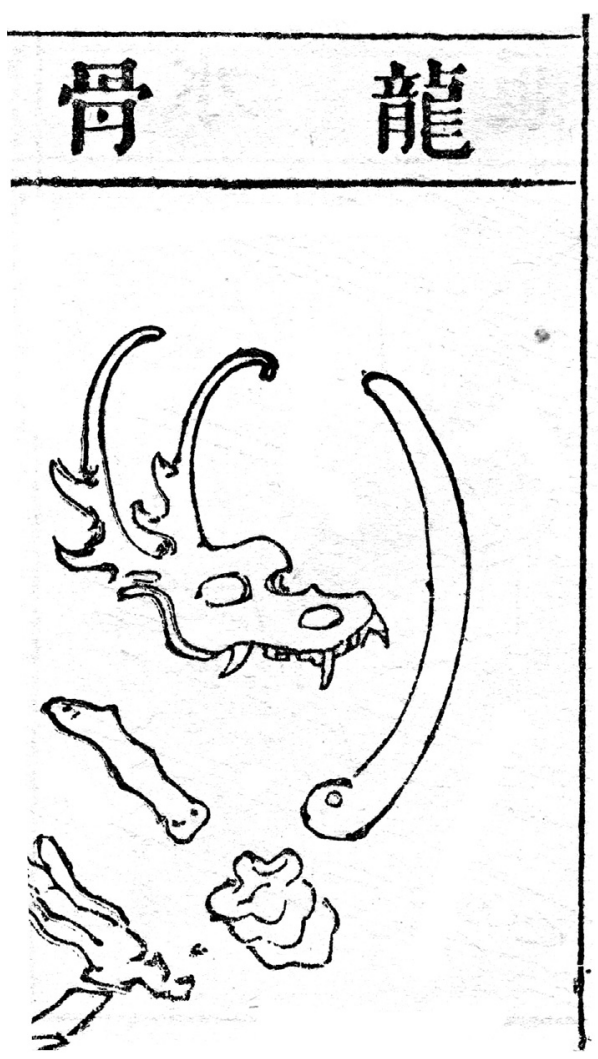

Fig. 2b 


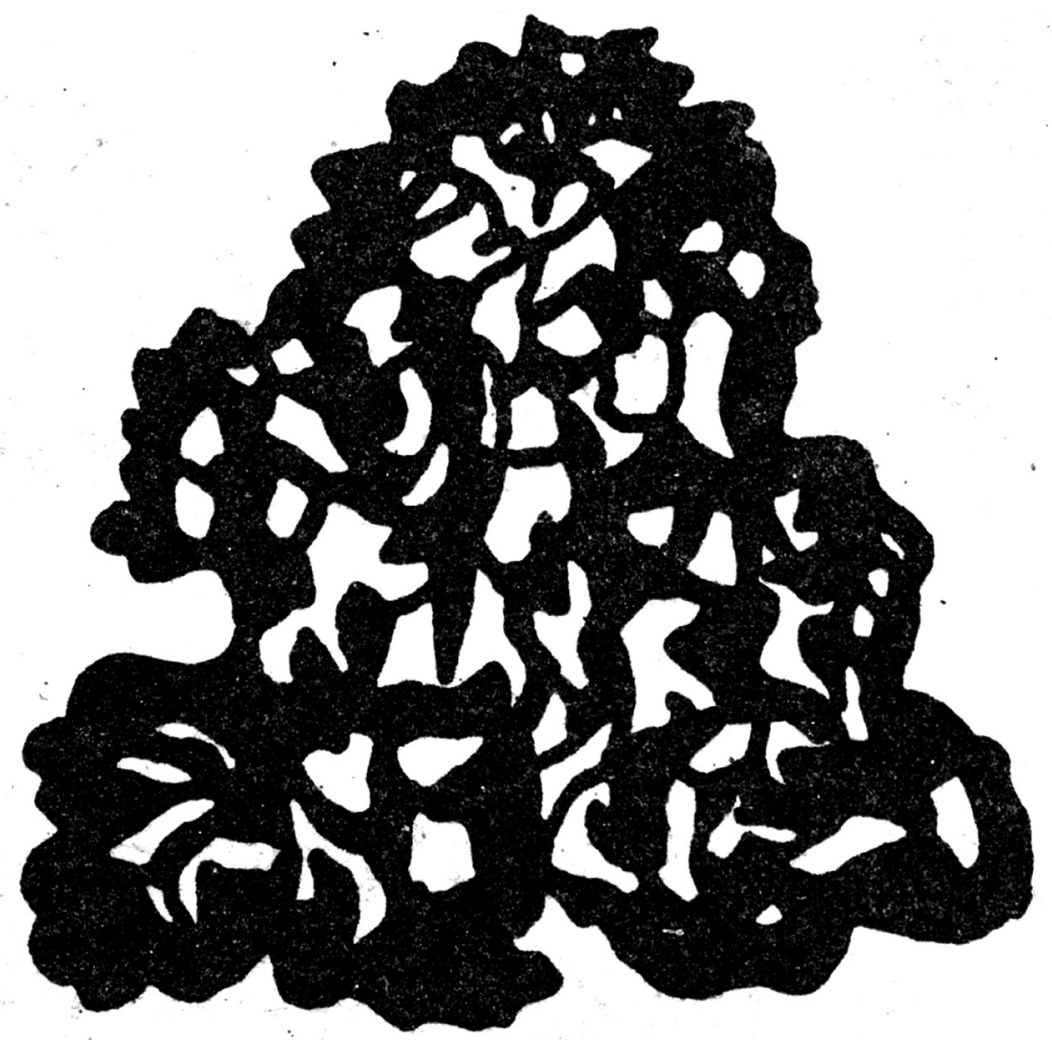

Fig. 2c

Fig. 2. Dragon bones in a) Bencao tu jing and b) Bencao gangmu (1885) c) flying squirrel dung ( $w u$ ling $z h i$ 五靈脂) (Bencao tu jing)

Sources:

* Shang Zhijun 向志钧 ed., Bencao tu jing 本草图经 (Hefei: Anhui kexue jishu chubanshe, 1994), 423, 526.

* Bencao gangmu (Shanghai: Shangwu yinshuguan, 1933), vol. 1, 42. 
copied and perpetuated in later editions in the understanding that this visual imprint had now become canonical and hence immune to new circumstances, new insights or new reports on its use as a drug? ${ }^{45}$ If so, we must assume that later bencao compilers who were re-examining, re-editing, and correcting drug entries with a new curiosity did not attach much value to the accuracy and practical function of illustrations.

In any case, this scenario could account for the possibility that the illustrations recognisable to Li Shizhen or his sons may have gone back in time as far as the original drawings in the Tu jing bencao. Although nowhere in his own text does Li make reference to accompanying illustrations, he did personally express misgivings about the illustrations he saw. He speaks of a mismatch between text and illustration, of illustrations without explanations and of drugs being described with missing illustrations, or, even stronger, 'in some cases the explanations are correct but the illustration is wrong (buo shuo shi tu $f e i$ 或說是圖非)'. ${ }^{46}$ And indeed Ai Cheng's 艾是 preface to the 1108 edition of Daguan bencao partly justifies its compilation on the grounds that pharmaceutical knowledge needs constant updating; that medicines, when identified mistakenly, can be more harmful than the illnesses they try to cure; and that illustrations together with prescriptions play a vital role in assisting less experienced medical men to recognise the effectiveness of a drug. ${ }^{47}$ But although Song editors were capable of producing coloured illustrations of plants recognisable up to the present day, judging by Li Shizhen's comments, it is questionable whether such illustrations were taken to reflect zoological, botanical, or pharmaceutical information not already present in text.

The early sixteenth century saw another highlight in the history of bencao illustrations in the form of the Bencao pinhui jingyao 本草品彙精要 (completed in 1503-5) which contains 1,358 colour illustrations. Some of the illustrations in this work resemble those in the Daguan bencao but they are executed with greater precision, include drawings that set plant and animal drugs in their natural surroundings, or illustrate the procedures of their production into drugs. The work, however, remained hidden from the public in the imperial collection for almost two centuries until Emperor Kangxi

${ }^{45}$ As much is admitted for instance in the preface to the Shaoxing bencao 紹興本草 (1159) which states: 'As to the shape and appearance [of the items discussed] we have based [our own presentation] on old illustrations'. See Unschuld 1986, pp. 79-80. For some examples, see Karow 1956.

46 Bencao gangmu (Shanghai: Shangwu yinshuguan, 1933), 5.1 ('Xu li, shang'序例上), p. 6.

47 For the preface in translation, see Unschuld 1986, pp. 72-3. 
康熙 (1655-1723) rediscovered its valuable existence and commissioned copies of parts of the illustrations to be made..$^{48}$

These then appear to be the main direct precursors to the Bencao gangmu illustrations. Yet other works, outside the main bencao corpus, also contained valuable illustrations. Important in this respect is Hu Sihui's 忽思慧 (14th century) Yinshan zhengyao 飲膳正要 (Propriety and Essentials in Eating and Drinking), a materia dietetica and cookbook in three chapters published in 1456 and presented to the Mongol court. ${ }^{49}$ It contains well over 200 illustrations which include not only images of isolated items but also illustrated narratives. For instance, one illustration shows variously black-and-white coloured goats with the caption 'strange transformations in animals' (qin shou bian yi 禽獸變異) in the top right corner (Figure 3). Captions appear to be essential to understand the illustration which otherwise would be of little informative value for the dietary physician or cook. The explanatory text to this particular illustration reads:

The shapes and species of animals originate from their basic bodily form just as their natures are divided into poisonous and non-poisonous varieties. Even more so in the case of strangely shaped creatures born through anomaly, how could these be without poison?! If one is not careful about what one eats it will result in one becoming ill. This constitutes not looking into things. ${ }^{50}$

Next follows a list of 26 anomalous animals or animal products to be avoideda white horse with green hooves, a crab with only one claw, meat that moves when put in water, a sheep with a hole in its liver, etc. Throughout the work, illustrations are largely didactic and given that the text invariably comments on the toxicity or lack thereof in certain foodstuffs, this makes sense. A number of captions stride away from simply giving dietetic or medicinal advice. For instance, the entry on the tiger states: 'If one eats tiger meat and enters the mountains the tigers will be afraid when they see you. It wards off the thirty-six kinds of mei demons.' The illustration of a rhinoceros is accompanied by a statement that eating it ensures that one does not get lost in the mountains; and a broth of mandarin duck meat makes couples fall in love. ${ }^{51}$

${ }^{48}$ For a summary of its contents and transmission, see Unschuld 1986, pp. 128-45. See also Métailié 1998. On colour illustrations in Ming bencao, see further Zheng Jinsheng 鄭金生 2003; Xie Zongwan谢宗万(ed.) 2001.

49 This Ming edition, which forms the basis of all later versions, is included in the Sibu congkan. For a full translation and study, including the original text and reproductions of the woodcut illustrations, see Buell and Anderson 2000.

${ }^{50}$ Liu Yushu 劉玉書 (ed.) 1989, pp. 102-3; cf. Buell and Anderson 2000, pp. 371-2 (illustration and text); 443-5 (translation). My translation differs.

${ }^{51}$ Buell and Anderson 2000, p. 464 (16A), p. 466 (18A), p. 475 (26B). For a summary of imagery associated with mandarin ducks in pre-Song sources, see Luo Yuan 羅願 (1136-84 CE), Erya yi 爾雅翼 (Congshu jicheng ed.), 17.187-8. 


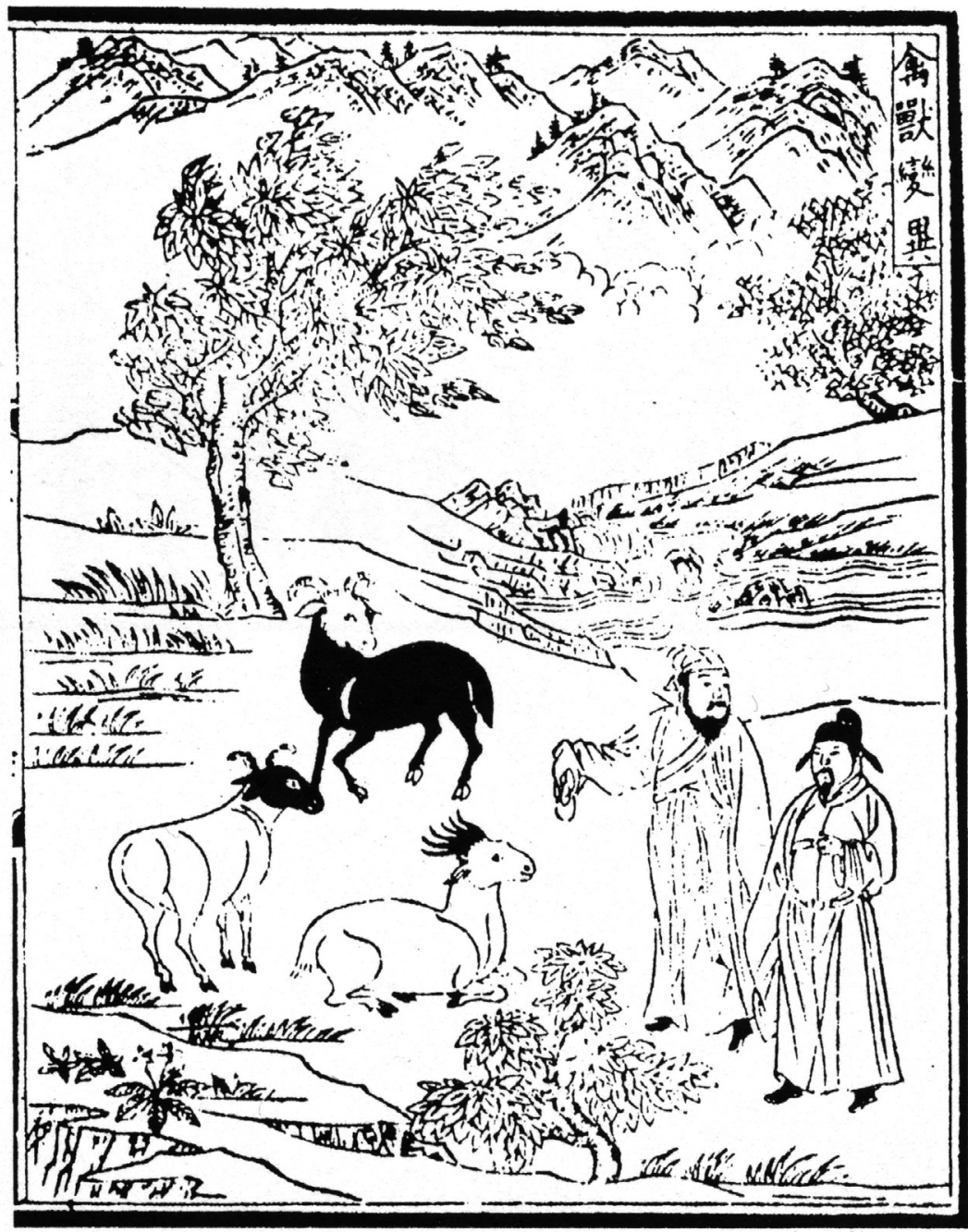

Fig. 3. Yingshan zhengyao

'Strange animal transformations'.

Source: Yinshan zhengyao (preface by Zhu Qiyu 朱祁鈺, Ming), in Zhongguo gudai banhua congkan er bian 中國古代版畫叢刊二編 (Shanghai: Shanghai guji, 1994), vol. 2, 205. 
Some illustrations show detail that seems directly related to the dietetic advice given in the text. For instance, an image of a shrimp with clearly marked whiskers illustrates an entry insisting that shrimp without whiskers should not be eaten. ${ }^{52}$

Another important category of writings, worth a separate study, are illustrated veterinary manuals. Some of these contain illustrations of anatomical animal parts; others depict animals displaying ailments and include physiognomical charts. Examples include the Yuan Heng liaoma ji 元亨療馬集 (Collation of Horse Ailments by [Yu Ben 喻本]yuan 元and [Yu Ben] heng 亨)(1608), the Xinke ma shu 新刻馬書(Newly Cut Writings on the Horse; by Yang Shiqiao 楊時喬 et al., completed 1594), the Yuan dynasty Xinke zhushi ma niu tuo jing daquanji 新刻注釋馬牛䭾經大全集 (Newly Cut and Annotated Comprehensive Collectanea of the Canon on Horses, Oxen, and Camels), and others. ${ }^{53}$ Anatomical illustrations or illustrations of body parts were not exclusive to this genre of texts. Ritual manuals and explanatory commentaries on the ritual classics also preserve some examples. For instance, the rudimentary drawings inserted in the $L i s h u$ 禮書, a text attributed to the Song scholar Chen Xiangdao 陳祥道 (fl.1053-93), include a drawing of a sacrificial ox with names identifying the various parts of its skeleton as well as simple drawings of lungs offered up in sacrifice. ${ }^{54}$

So by the time Li Shizhen embarked on his life-time project, bencao and related works had been illustrated for centuries. Illustrations had been copied, edited, standardized, and, in some cases, we must assume, updated with more detail. They would continue to be produced throughout the late Ming, Qing and into the twentieth century. ${ }^{55}$ Yet, unlike the successive reworking of texts and the endless accretion of commentaries, modifications to illustrations remained relatively minor to stagnant.

52 Buell and Anderson 2000, p. 481 (32A).

53 A notable illustrated manuscript of Korean origins is the Xinbian jicheng ma yi fang niu yi fang 新編集成馬醫方牛醫方completed in 1399 (printed 1633). See Kim Sin-gŭn 金信根 (ed.) 1992. Xinke ma shu is readily available in a recent 1984 edition by Nongye chubanshe; Yuan Heng liaoma ji (also known as Niu ma jing 牛馬經) in a 1957 edition by Zhonghua shuju; Xinke zhushi ma niu tuo jing daquanji, with annotations by Guo Huaixi 郭懷西 (fl. ca. 1785), in a 1983 edition published by Nongye chubanshe. Some of the illustrations in these texts are attributed to or purportedly based on illustrations in the oldest transmitted veterinary manual to date, the Tang dynasty Si mu an ji ji 司牧安焂集. For a recent reconstruction of this text, see Pei Yaoqing 裴耀卿 (1911-71) (ed.) 2004.

54 See Li shu, Siku quanshu zhenben wu ji 四庫全書珍本五集 ed., (Taipei: Shangwu, 1974), $77.1 \mathrm{~b}, 77.2 \mathrm{a}-2 \mathrm{~b}$.

55 One highlight, shortly after the publication of the Bencao gangmu, was the Tu xiang bencao mengquan 圖像本草冢荃 (Illustrated Abolition of Ignorance in Pharmaceutics; 1628). See Unschuld 1986, pp. 247-8. 
Reported numbers of illustrations in the early editions of Bencao gangmu range from 1109 to $1160 .{ }^{56}$ The first and original edition, also known as the Jinling 金陵 edition published in Nanjing in 1596 by Hu Chenglong 胡承龍, contains two separate chapters of illustrations from the hand of Li Shizhen's son, Li Jianyuan. Largely based on the Zhenglei bencao, they contained few actual models and were criticized for their lack of detail and regional variation. They are copied without significant innovations in the Jiangxi 江西 edition of 1603 but here they were placed at the beginning of each chapter to which they belong. ${ }^{57}$ Two later editions represent successive re-workings of the illustrations. The Hangzhou 杭州 or Qian Shi 錢氏 edition of 1640 includes three chapters totalling 1,110 illustrations from the hand of Lu Zhe 陆吉. They are the basis for the illustrations in the 1782 Siku quanshu edition. The late Qing Weiguzhai 味古齋 edition (1885) has three chapters with illustrations (ca. 1122 in total) by Xu Gongfu 許功甫, largely based on the illustrations published in 1640. And although some changes are manifest, especially in the illustrations of plants, overall continuity and minimal variation links these different sets of illustrations. ${ }^{58}$ The majority appear to be imitations of previously transmitted illustrations and only a few appear to be based on new observations or real models. ${ }^{59}$ Unlike Europe, as Paul Unschuld points out, the history of medical illustration in China shows greater continuities: 'Changes in China between the Han period and the end of the Imperial period were always within the system, never of the system.' ${ }^{60}$

56 For recent accounts of Bencao gangmu editions, see Hubei sheng zhongyi yao yanjiuyuan ed. 1988, pp. 68-100; and Ma Jixing 马继兴2003 (summarised in Wang Jian 王剑 (ed.) 1996, pp. 37-8).

57 Carla Nappi suggests that the changes in illustrations between the 1596 and 1603 editions are nevertheless significant and she lists the names of 19 entries (without the illustrations) in support. See Nappi 2006, pp. 77-80. Clearly some illustrations were changed and other minor alterations no doubt resulted from the re-cutting of the woodblocks for the 1603 edition. Yet I remain unconvinced that these reflect a fundamental change in the modes of observation by the illustrator(s), let alone that they might be indicative of a new understanding of the relationship between text and illustration. Also, statistically, these altered illustrations make up a relatively small share in the total number of (reported) illustrations.

${ }^{58}$ As Métailié and Haudricourt comment: 'So it took nearly three centuries and about forty editions before some innovation appeared in the illustrations of the plants in China's most famous materia medica'. See Métailié and Haudricourt 1994, p. 403.

59 My statistics are based on a detailed discussion in Xie Zongwan 谢宗万 1985.

${ }^{60}$ Unschuld 2000, p. 103. 


\section{How to look: Modes of visuality}

Of course, Li Shizhen's project, as others that preceded and followed it, was more than simply a materia medica. It includes, among other recipes, descriptions that sometimes appear akin to what one might find in a herbal, bestiary or lapidary in the world of the Linceans. And one might argue that its taxonomic ambitions could be as rigorous, albeit conceptually different, as those of a zoologist or botanist in Renaissance Europe. Bencao illustrations therefore should not be judged solely on their pharmaceutical veracity. Yet, when Joseph Needham spoke of the 'relatively no non-sense content' of bencao illustrations ('what nonsense there was, never at any time got into their illustrations') are we to take his comment as a silent approval of their reliability for the practical purposes described in its recipes? ${ }^{61}$ A key question that remains is whether these illustrations are medically or pharmaceutically expedient at all. Since they were highly conventional, mimetic and not necessarily based on contemporary observations, to what extent did they add to the pharmaceutical knowledge reported in the text? Would the user of an un-illustrated bencao have less clarity about the information conveyed in its written entries?

Much depends on whether historians of medicine choose to discuss developments in so-called 'medical' illustration separately from developments in printing, painting and technical illustration that took place in the centuries from the Song to the late Ming. The utility of bencao illustrations can be usefully evaluated in this historical and social context. First, there is the issue of artistic innovation. As Lothar Ledderose has shown, in creative techniques as varied as bronze casting and calligraphy, a salient feature of artisan production in traditional China is its reliance on modular production. 'Modular thought' implies that creative authority partly derives from combining and reworking existing models and prototypes. As in the world of the written word, visual mimesis was often the rule rather than exception. Even if artists expressed disdain for modular production, many painters, for instance, still worked along modular lines in creating their compositions by combining existing motifs. ${ }^{62}$

In the case of the naturalist one might surmise that modularity in the realm of the visual stood in contrast to expectations that befell the textual scholar. Whereas the compiler or editorial team of a bencao could demonstrate encompassing scholarship through the exegetical knack of wading through and commenting on constantly accreting textually transmitted knowledge, the illustrator for his part conceived of his task as one of faithfully reproducing

${ }^{61}$ Needham 1986, p. 225.

62 Ledderose 2000. 
illustrations from the past. To do otherwise would mean that he either had to (re-)invent an image from scratch or, alternatively, go out and make observations in nature. The assumption that the illustrator went out to do observations is problematic. Many species to be illustrated would hail from regions far beyond his atelier; illustrators were first and foremost commissioned artists and not necessarily naturalists (although some were closely involved). Even to the keen observer, animals would have formed a particularly difficult category for representation since they moved, changed habitats according to the seasons, and were less 'fixable' against a real or imaginary landscape than rocks or plants.

In addition to modularity, there is the issue of abstraction in visual culture. In a study of technical drawings, Peter Golas summarizes changes in painting from the early Song onwards as a trend showing 'a growing prejudice against the inclusion of accurate and detailed visual information, a clear retreat from realism'. He goes on to point out that this reorientation away from realism in painting influenced other forms of illustration. One important element was that models for illustration were no longer real objects but instead, imitations and copies of earlier drawings: 'The non-representational, sometimes almost abstract character of so much of Chinese painting and drawing meant that there was little emphasis on "getting it right" in the sense of making what was portrayed resemble as closely and convincingly as possible what the viewer saw looking at the object itself.' ${ }^{63}$ Commenting on agricultural illustrations, Francesca Bray likewise concludes that 'when it came to practical, technical matters like farming, it seems that those educated Chinese who recorded changes or improvements [to existing illustrations] were satisfied with the power of words to convey material processes, and felt no need or desire to resort to graphics. ${ }^{64}$

Unlike in the case of machines, isolated illustrations of drugs do not illustrate how a particular plant or animal drug works. In the case of animals, plants and minerals, technical information conveyed visually, as for instance in the illustrations in Bencao pinhui jingyao, is limited to representing production procedures. Isolated illustrated models, however, merely identify creatures and otherwise normal looking objects to the user as medically potent. Likewise, part of the aura and efficiency of a drug might be augmented by illustrating it. The dog depicted in a pharmacopeia is not the guardian dog or intimate companion of the household sphere but an objectified product to be used for medicinal purposes. Yet the didactic motivation underlying the

63 Golas 2005, pp. 199, 200. See also the conclusion to Golas 2007.

64 'Agricultural Illustrations: Blueprint or Icon?', in Bray et al. (eds) 2007, p. 552. 
illustrations remains intimately linked to the recipes in the text. Bencao illustrators must have assumed that readers make visual connections between the creatures mentioned in the recipes and those illustrated. In this sense, the medical illustration differs from the prescriptive technical illustration. ${ }^{65}$

Readers' expectations towards Bencao gangmu illustrations should also be viewed in their historical moment, namely, the visual culture and book economy of late Ming China. Meanings associated with the term $t u$ 圖 had changed over time. By Ming times, $t u$, frequently translated as picture, was also used to denote a configuration of text alone. Craig Clunas suggests that 'chart' would be more accurate as a translation and notes that the broad usage of the notion of $t u$ evolved against the background of a debate from the sixteenth century onwards that focused on the adequacy of representation and 'the contested primacy of visual and purely verbal explanations of phenomena'. ${ }^{66}$ Ming elites had largely lost interest in public pictorial formats such as the mural or wall painting. Yet while the world of book illustrations had unlocked a private pictorial sphere with a quantity of pictorial representations greater than ever before, Ming commentators wrote surprisingly little about them. Ming titles that announced themselves as illustrated without the pictures being essential to the text also did so for external reasons. One important motivation, Clunas highlights, was commercial, to 'add to its allure in the marketplace' ${ }^{67} \mathrm{~A}$ logical consequence is that the illustrator's aspiration to display his artistic repertoire could detract from the goal of accurate representation. Likewise, the cost of producing richly detailed illustrations may account for the fact that only half of the nearly 2,000 drugs in Bencao gangmu were ever illustrated. ${ }^{68}$ In sum, what motivates the creation and publication of bencao illustrations is as important a question to consider as our quality assessment of the illustrations themselves.

Charted against the background of developments in fiction and the illustrated vernacular print, Li Shizhen lived at the end of a transitional period between the use of printed illustrations to explain a text or narrative and a later phase in which illustrations mainly fulfilled a decorative and aesthetic function. ${ }^{69}$ In illustrated fiction, illustrators often repeated conventional elements. Reading habits informed the context in which pictures were judged, as Robert Hegel points out: 'the quality of book illustrations was adjudged by the degree

\footnotetext{
${ }_{65}$ On the principles underlying technological illustration, see further Golas 2001.

66 Clunas 1997, pp. 105, 108.

${ }^{67}$ Clunas 1997, pp. 34-5.

${ }^{68}$ On the ascendancy of the imprint over the manuscript and shifts in production costs during this period, see McDermott 2006, chapters 1 and 2.

69 See McLaren 1998, pp. 58-9.
} 
of perfection of the variations on the conventional rather than by uniqueness; repetition of familiar stock elements allowed quick recognition and ease of comprehension and appreciation. ${ }^{70}$ If illustrators of fiction crafted their images with stock ingredients, it is not impossible to conceive that bencao illustrators could rightfully do the same. Readers of illustrated fiction may have been familiar with a storyline to the point that the relationship of illustrations to their text had become self-evident or even redundant. In the case of the illustrator of a naturalist work, one would expect that a reader judged the quality of illustrated animal or plant drugs at least partly by his own observations, environment or previous reading record. Yet this would apply only if this reader was a practitioner intending to use the text as a manual. To others, the presence of sketchy drawings of stones, worms or bees might even have been seen as vulgar and serving a readership for whom the recipes were incomprehensible or insufficient without. The illustrated book was not infrequently condemned as a luxurious item that detracted from the quality of a text. As Clunas notes, 'pleasure, the desire to look, is not invoked in Ming texts except negatively, as a licentious act to be censured and avoided. ${ }^{71}$

\section{Naturalist illustration}

So the doubts expressed by naturalists in Europe on the use of pictures as adequate media for the purpose of classification-from Galen, Pliny to Linnaeus ${ }^{72}$ - might have found a sympathetic ear in Li Shizhen. What unites most pictorial representations of animals in the sources discussed above is their emphasis on the outward appearance of these creatures. Whereas the texts clearly reveal that, by Li Shizhen's time, physicians had discovered the pharmaceutical workings of the insides of animals, it is equally clear that they had not transferred this knowledge with the same sense for detail into visual media. Illustrations barely touched the surface of the pharmaceutical ideas that could be expressed in text. Rarely did they invite the reader to ponder on the anatomy or internal structure of animals as drugs. Instead, illustrators aligned themselves with a tradition that saw pictures as a complement to the identification of objects and, in many cases, the rectification of nomenclature. At least in this sense, natural inquiry was firmly tied to Confucian and neo-Confucian epistemological paradigms such as the 'rectification of names' (zheng ming

\footnotetext{
${ }^{70}$ Hegel 1998 , p. 312.

71 Clunas 1997, p. 39.

72 Freedberg 2003, pp. 5-6.
} 
正名) and 'investigation of things' (ge wu 格物).${ }^{73}$ Indeed one might argue that bencao illustrations, rather than illuminating the text, could also obfuscate and confuse the user of it. Whereas the consumer of a textual recipe-a medium suited to impart several dimensions of knowledge such as precedent, usage, circumstance, variation - is less likely to confuse one entry with another, the beholder of an illustration might not be able to distinguish between them without having recourse to a text or name caption. Without more information on the various modalities in which illustration and text came together, it remains difficult to assess their intended function.

To ascribe the lack of morphological detail in bencao animal illustrations to a dearth of physiological or anatomical expertise is probably imprecise. Techniques of dissection and skills at the anatomical identification of animal parts are attested in ritual texts dealing with sacrifice and engrained in dietetic culture since antiquity. An observing eye also underlies a degree of detail evinced in some animal depictions preserved in illustrated encyclopaedia that are roughly contemporaneous to Bencao gangmu such as Wang Qi's 王圻 (fl. 1565-1614) Sancai tuhui 三才圖會 (Assembled Pictures of the Three Realms). ${ }^{74}$ The richly illustrated veterinary treatises mentioned above likewise contradict poor expertise. There the viewer is invited to focus on an anatomical locus or organ, often indicated by a caption and a connecting line (Figure 4). To be sure, these texts serve a different purpose in that the illustrator tries to depict physical or behavioural abnormalities against a received model of a normal or healthy horse or ox. But it is precisely here that bencao illustrations depart from their effectiveness as proper medical or pharmaceutical tools. Only a few depict anatomical parts or organs and many animals, stones and plants are hardly distinguishable were it not for the name printed on the illustration (Figure 5). Behind their arrangement lurks the principle that once the reader is able to associate the depicted drug with a primary name, the physician or reader grasps all workings and lore associated with it. Once pictured, a creature is no longer unknown. In that sense the illustration can be seen as a commentarial extension of the text, or as yet another type of 'nomenclature' that serves to circumscribe its properties. In the case of Li Shizhen, they were posthumous, added later and not part of the original copy delivered to Nanjing for cutting shortly after his death. It is doubtful that he saw illustrations as an essential part for the understanding of his work.

73 On Li Shizhen's recourse to 'naming' as an epistemolocial paradigm in a Ming context, see also Elman 2007, 143-6. Its antecedents are discussed in Sterckx 2005.

${ }^{74}$ For a selected survey, see Goodall 1979, pp. 95-126. Note, however, that an equal number of Sancai tuhui illustrations closely resemble the typology of bencao illustrations, which suggests that some were sourced from the bencao tradition. 


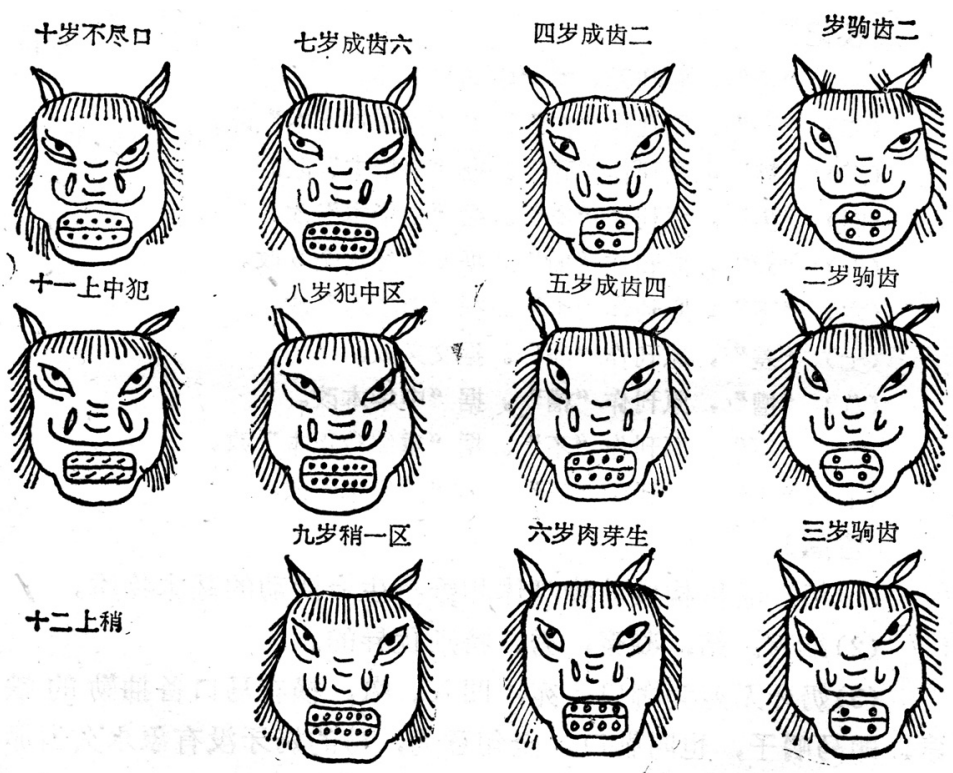

Fig. $4 \mathrm{a}$

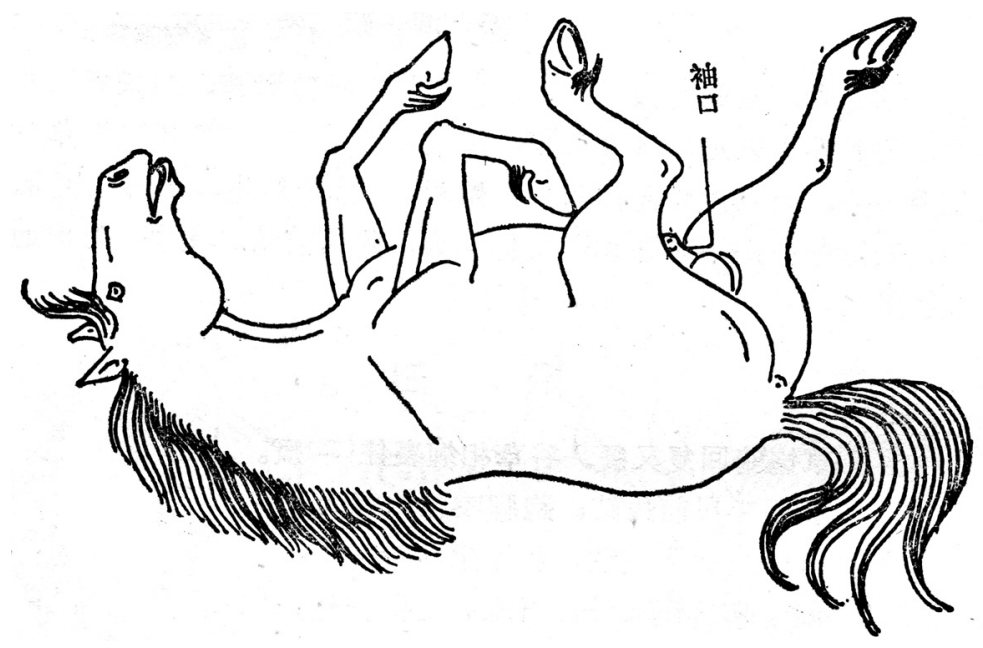

Fig. $4 \mathrm{~b}$

Fig. 4. Yuan heng liao ma ji

a) Determining the age of a horse by dental record.

b) Horse scrotum.

Source: Yu Chuan 于船 et al. eds., Yuan heng liao ma ji jiaozhu 校注 (Beijing: Beijing nongye daxue, 1990), 85, 127. 


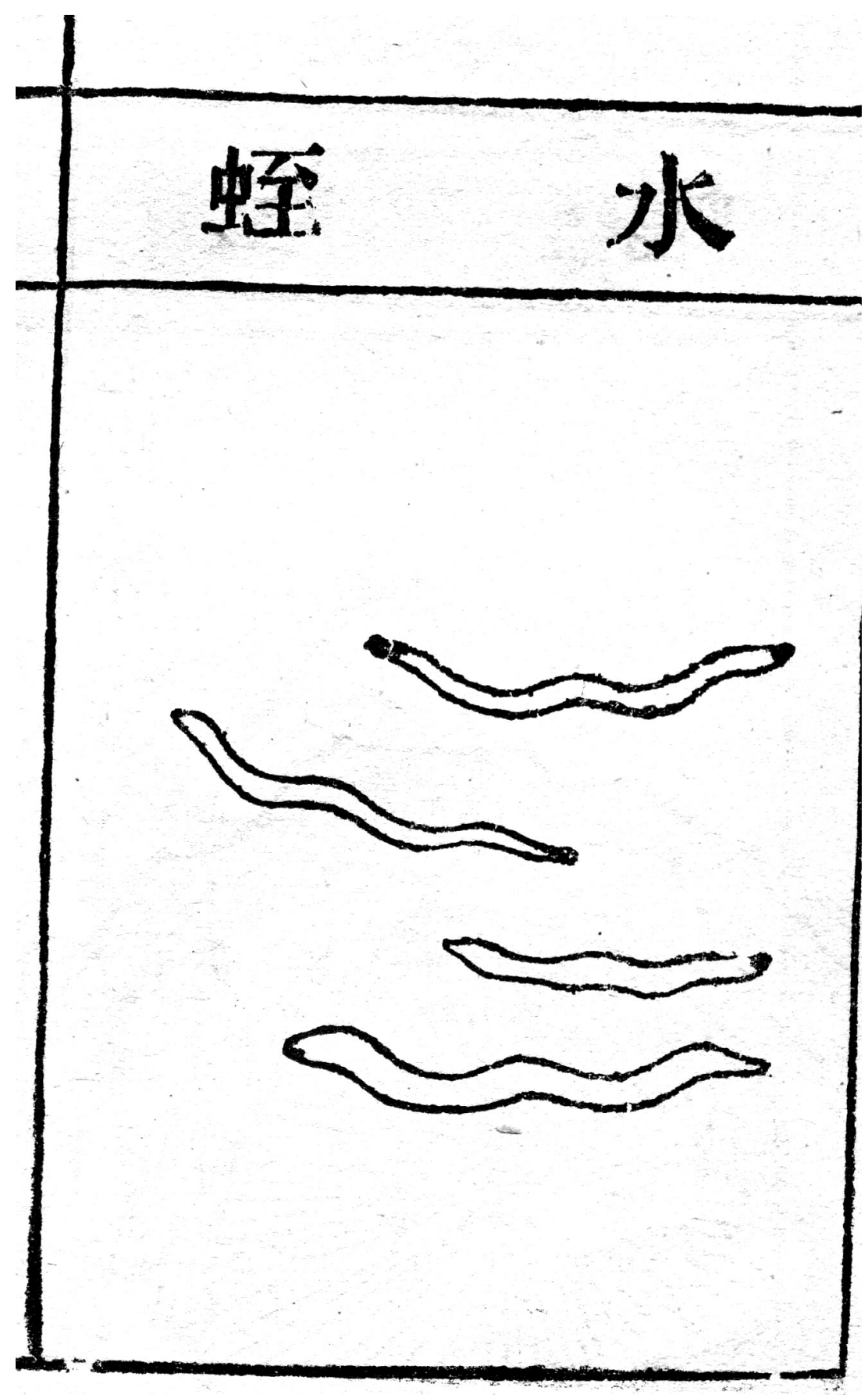

Fig. 5a 


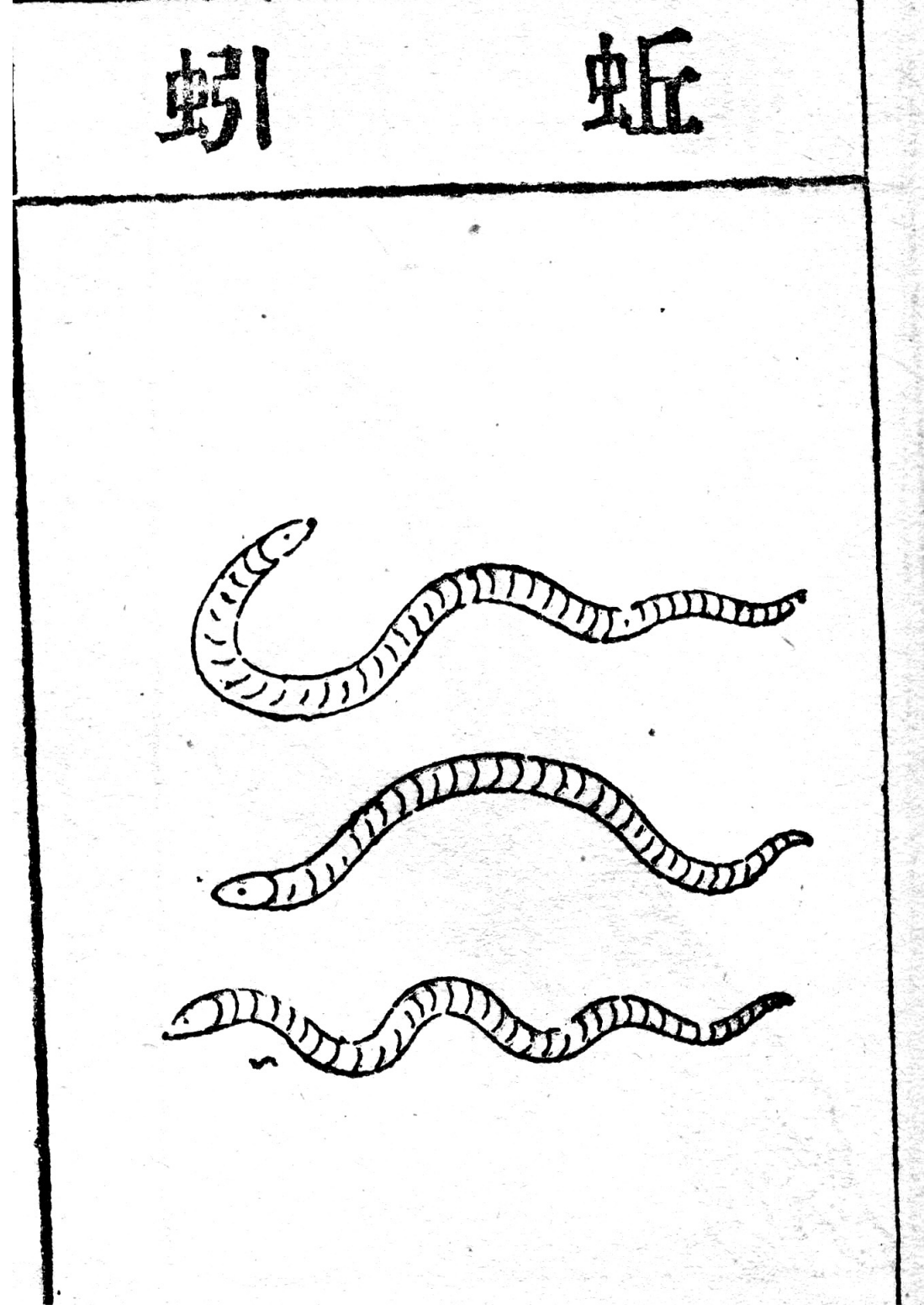

Fig. 5a bis 


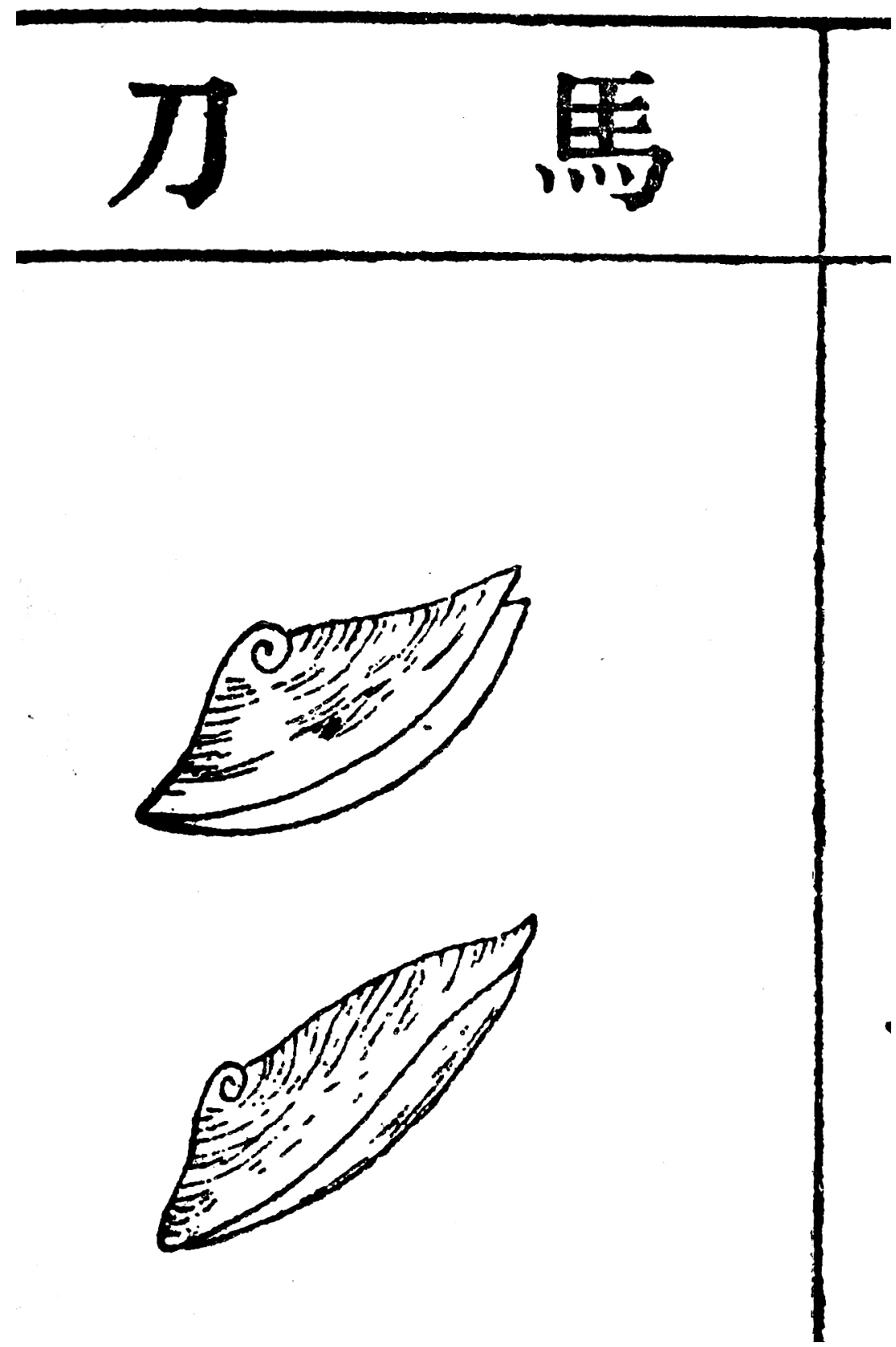

Fig. $5 b$ 


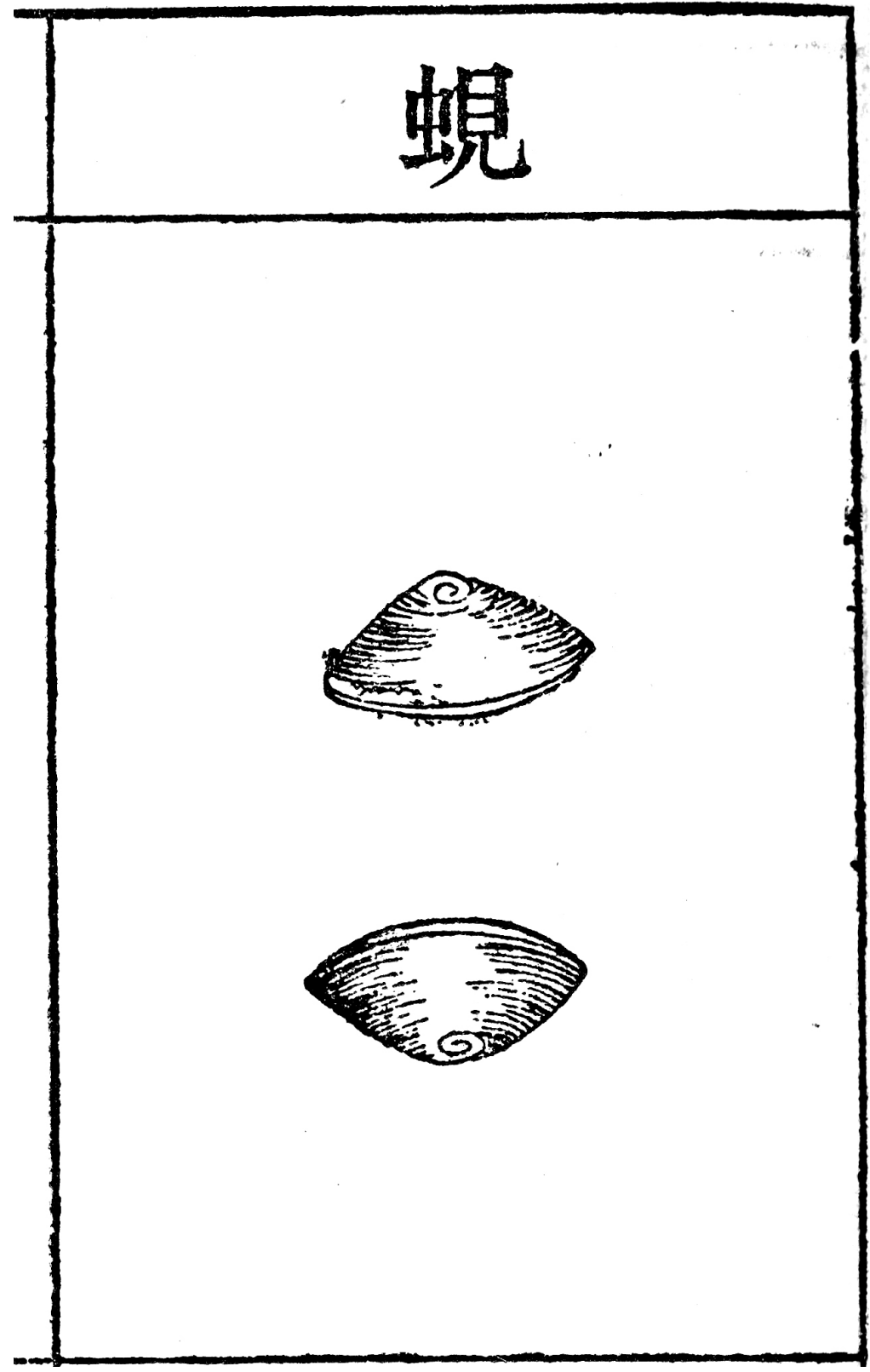

Fig. $5 \mathrm{~b}$ bis 


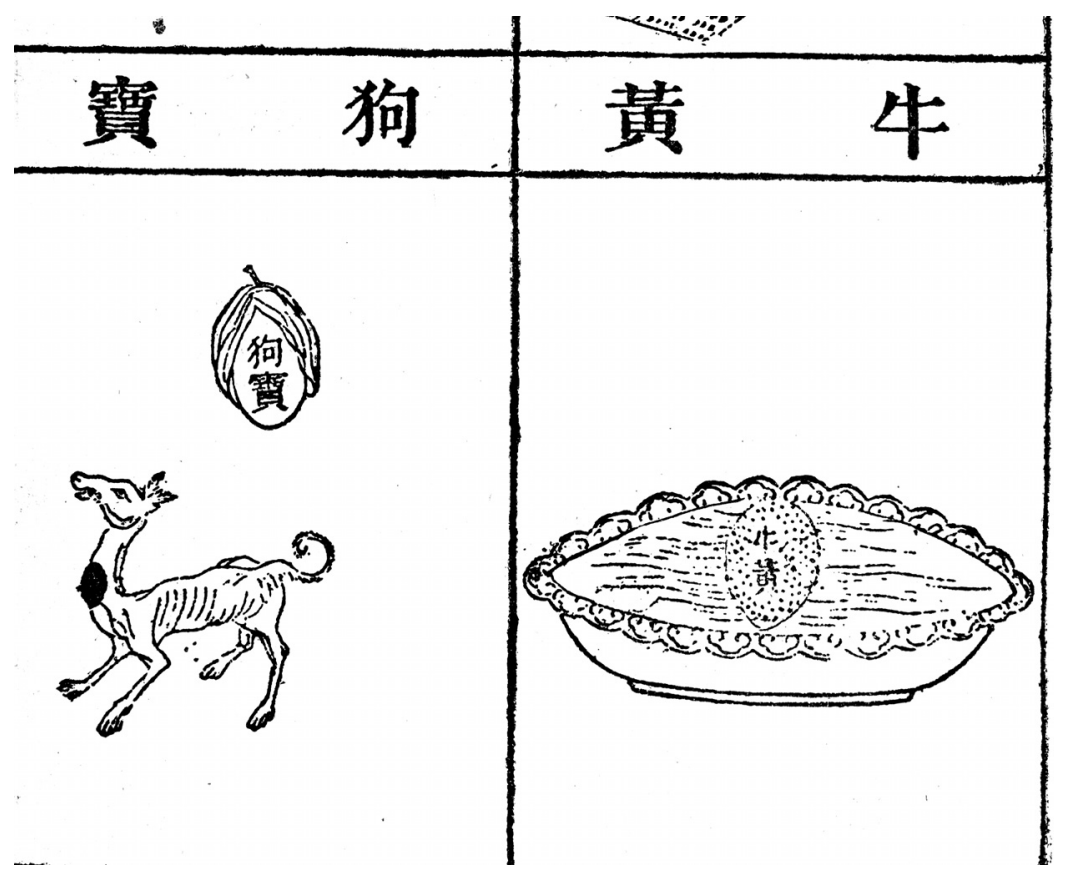

Fig. 5c

Fig. 5. Bencao gangmu (1885)

a) Leech (shui zhi 水蛭) versus earthworm (qiu yin 蛏蚓).

b) 'Giant mussel' (ma dao 馬刀) versus 'small' clam (xian 蜆).

c) Cow bezoar (niu huang 牛黄; calculi bovis) and dog bezoar (gou bao 狗寶; calculi canis).

Source: Bencao gangmu (Shanghai: Shangwu yinshuguan, 1933), vol. 1, 34, $41,64,65,90$. 
Not much has been written on the bencao illustrations. In the early 1890 s, the German missionary and sinologist Ernst Faber (1839-99) commented that its 'authors were commonly more familiar with books than with nature, and the block-cutters had no understanding of either' ${ }^{75}$ Indeed, a century later many of the basic questions surrounding the origins, style and quality of bencao illustrations remain. We do not know what factors determined the illustrators' choice to represent one drug over another or how to assess the results achieved by the pictorial representation of a drug. Were illustrators reconstructing or resuscitating images on the basis of their reading of the text? To what degree was the bencao illustrator limited by his form of presentation and how did the physician plumb beneath the bodily surface of the creatures drawn before him? If anything, such questions should encourage historians of Chinese medicine not just to explore 'what' to look at and search for the physical referent of an illustration, but also to pose the question 'how' a reader or user of materia medica was meant to look at them.

\section{References}

Barnard, N. 1973, The Ch'u Silk Manuscript: Translation and Commentary, Canberra: Monographs on Far Eastern History, Australian National University.

Bray, F. 2007, 'Agricultural Illustrations: Blueprint or Icon?', in Bray F. et al. (eds), Graphics and Text in the Production of Technical Knowledge in China: The Warp and the Weft, Leiden: E. J. Brill.

Bray, F., Dorofeeva-Lichtmann V. and Métailié G. (eds) 2007, Graphics and Text in the Production of Technical Knowledge in China: The Warp and the Weft, Leiden: E. J. Brill.

Buell, P. and Anderson E. 2000, A Soup for the Qan: Chinese Dietary Medicine of the Mongol Era as seen in Hu Szu-hui's Yin-shan Cheng-yao, London and New York: Kegan Paul International.

Chen Qiyou 陳奇猷 (ed.) 1991, Han Feizi jishi 韓非子集釋, Gaoxiong: Fuwen.

Chen Songchang 2006, 'Jianbo “Tianwen qixiang za zhan” yanjiu san ti’ 簡帛 “天文氣象雜占” 哳究三題, in Wuhan daxue jianbo yanjiu zhongxin (eds), Jian bo 簡帛, vol. 1, Shanghai: Shanghai guji, 449-58.

Chen Songchang 陳松長 1993, 'Mawangdui Han mu bohua “shenqi tu” bianzheng' 馬王堆漢 墓帛畫 ‘神祇圖’ 辨正, Jiang Han kaogu, 1, 88-92.

Cigliano, M. 1996, 'Yang Shen (1488-1559), un letterato in esilio e la rivalutazione delle culture minoritarie dello Yunnan', in Carletti S. M., Sacchetti M. and Santangelo P. (eds), Studi in Onore di Lionello Lanciotti, Napels: Universitario Orientale, vol. 1, 353-76.

Clunas, C. 1997, Pictures and Visuality in Early Modern China, London: Reaktion.

Creel, H. G. 1974, 'Shenzi 申子', in Creel H. G., Shen Pu-Hai. A Chinese Political Philosopher of the Fourth Century BC, Chicago: University of Chicago Press.

Dorofeeva-Lichtmann, V. 2007, 'Mapless Mapping: Did the Maps of the Shanhai Jing Ever Exist?', in Bray F. et al. (eds), Graphics and Text in the Production of Technical Knowledge in China: The Warp and the Weft, Leiden: E. J. Brill, 217-94.

\footnotetext{
75 See Fan Fa-ti 2004, p. 108 (quoting the Journal of the North China Branch of the Royal Asiatic Society).
} 
Elman, B. 2007, 'Collecting and Classifying: Ming Dynasty Compendia and Encyclopedias', in Bretelle-Establet F. and Chemla K. (eds), Qu'Etait-ce Qu'Écrire Une Encyclopédie en Chine?, Extrême-Orient Extrême-Occident, Hors Série, Saint-Denis: Presses Universitaires de Vincennes, 131-75.

Fan Fa-ti 2004, British Naturalists in Qing China. Science, Empire and Cultural Encounter, Cambridge, Mass.: Harvard University Press.

Fiskesjö, M. 2001, 'Rising from Blood-Stained Fields: Royal Hunting and State Formation in Shang Dynasty China', Bulletin of the Museum of Far Eastern Antiquities, 73, 48-192.

Fracasso, R. 1988, 'The Illustrations of the Shan hai jing: From Yu's Tripods to Qing Blockprints', Cina, 21, 93-104.

_ 1993, 'Shan hai jing', in Loewe M. (ed.), Early Chinese Texts: A Bibliographical Guide, Berkeley: Institute of East Asian Studies, 361-2.

_ 1996, 'Guo Pu e lo Shanhai jing', in Carletti S. M., Sacchetti M. and Santangelo P. (eds), Studi in Onore di Lionello Lanciotti, Napels: Universitario Orientale, vol. 2, 601-36.

Freedberg, D. 2003, The Eye of the Lynx. Galileo, His Friends, and the Beginnings of Modern Natural History, Chicago: University of Chicago Press.

Gao Guangzhen 高光震 1991, 'Bencao tu jing yuanliu kao' 本草图经源流考, in Su Kefu 苏克福 et al. (eds), Su Song yu Bencao tu jing yanjiu 苏颂与本草图经㸴究, Changchun: Changchun chubanshe, 209-16.

Golas, P. 2001, 'Technological Illustration in China: A Post-Needham Perspective', in Arrault A. and Jami C. (eds), Science and Technology in East Asia, Turnhout: Brepols, 43-58.

_ 2005, 'Technical Drawing in Ming/Qing China and in Renaissance Europe', in Jiang Xiaoyuan 江晓原 (ed.), Duo yuan wenhua zhong de kexue shi 多元文化中的科学史, Shanghai: Jiaotong daxue chubanshe, 199-208.

— 2007, "Like Obtaining a Great Treasure": The Illustrations in Song Yingxing's The Exploitation of the Works of Nature', in Bray F. et al. (eds), Graphics and Text in the Production of Technical Knowledge in China: The Warp and the Weft, Leiden: E. J. Brill, 569-614.

Goodall, J. A. 1979, Heaven and Earth: 120 Album Leaves from a Ming Encyclopedia: San-tsai t'u-hui, 1610, London: Lund Humphries.

Guo Fu 郭郛 2004, Shanhaijing zhu zheng 山海經注証, Beijing: Zhongguo shehui kexue chubanshe.

Harper, D. 1999, 'Warring States Natural Philosophy and Occult Thought', in Loewe M. and Shaughnessy E. (eds), The Cambridge History of Ancient China, New York: Cambridge University Press, 813-84.

— 2007, 'Communication by Design: Two Silk Manuscripts of Diagrams ( $T u$ ) from Mawangdui Tomb Three', in Bray F. et al. (eds), Graphics and Text in the Production of Technical Knowledge in China: The Warp and the Weft, Leiden: E. J. Brill, 169-90.

Hawkes, D. 1985, The Songs of the South, Harmondsworth: Penguin.

Hayashi Minao 林巳奈夫 1971, 'Chōsa shutsudo So hakusho no jūni kami no yurai' 長沙出土楚帛書の十二神の由來, Tōhō gakuhō 42, 1971, 1-63.

Hegel, R. 1998, Reading Illustrated Fiction in Late Imperial China, Stanford: Stanford University Press.

Hubei sheng zhongyi yao yanjiuyuan (eds) 1984, Li Shizhen yanjiu 李時珍研究, Guangdong: Guangdong keji chubanshe.

Hubei sheng zhongyi yao yanjiuyuan (ed.) 1988, Li Shizhen shishi kao 李時珍史实考, Guangdong: Guangdong keji chubanshe.

Iannaccone, I. 1996, 'Lo zoo dei Gesuiti: La Trasmissione scientifica del bestiario rinascimentale Europeo alla Cina dei Qing in Kunyu tushuo di Ferdinand Verbiest (1674)', in Carletti S. M., Sacchetti M. and Santangelo P. (eds), Studi in Onore di Lionello Lanciotti, Napels: Universitario Orientale, vol. 2, 739-64.

Kalinowski, M. 2003, Divination et société dans la Chine médiévale, Paris: Bibliothèque Nationale de France. 
Karow, O. 1956, Die Illustrationen des Arzeneibuchs der Periode Shao-hsing vom Jahre 1159, Leverkusen: Bayer.

Kim Sin-gŭn 金信根 (ed.) 1992, Sinpyŏn chipsŏng uma ŭibang · Umayangjŏ yŏmyŏkbyŏng chiryobang · Magyŏng ch'ojip ŏnhe · ünggol pang · ŭigwa sŏnseng an · ŭigwa p’alse po 新編集成牛馬醫 方·牛馬羊猪染疫病治療方·馬經抄集諺解·鷹鶻方·醫科先生案·醫科八世譜, Seoul: Yogang ch'ulp'an sa 驪江出版社.

Lackner, M. 1990, 'Die "Verplanung” des Denkens am Beispiel der T'u', in Schmidt-Glintzer H. (ed.), Lebenswelt und Weltanschauung im Frühneuzeitlichen China, Stuttgart: Franz Steiner, $133-56$.

Lai Guolong 2003, 'The Diagram of the Mourning System from Mawangdui', Early China, 28, 43-99.

Ledderose, L. 2000, Ten Thousand Things: Module and Mass Production in Chinese Art, Princeton: Princeton University Press.

Lewis, M. E. 1990, Sanctioned Violence in Early China, Albany: State University of New York Press.

Lewis, M. 2006, The Construction of Space in Early China, Albany: State University of New York Press.

Li Haixia 李海霞 2002, Hanyu dongwu mingming yanjiu 漢語動物命名研究, Chengdu: Ba Shu shushe.

Li Ling 李零1991, 'Mawangdui Han mu “shenqi tu” ying shu “bibing tu” 馬王堆漢墓 “神祇圖” 應屬 ‘避兵圖, Kaogu, 10, 940-2.

Li Ling 李零 2000, Zhongguo fangshu kao 中國方術考, Beijing: Dongfang.

Li Xueqin 李学勤 1994, 'Zai lun boshu shi-er shen' 再论帛书十二神, in Jianbo yiji yuxueshu shi 简帛佚籍与学术史, Taipei: Shibao, 58-70.

Liu, C. Y., Nylan M. and Barbieri-Low A. (eds) 2005, Recarving China's Past: Art, Archaeology and Architecture of the 'Wu Family Shrines', New Haven and London: Yale University Press.

Liu Keming 刘克明 2003, Zhongguo gongcheng tu xue shi 中国工程图学史, Wuchang: Huazhong keji daxue.

Liu Pansui 劉盼逐 (ed.) 1990, Lunheng jiaoshi 論衡校釋, Beijing: Zhonghua.

Liu Wendian 劉文典 (ed.) 1992, Huainanzi honglie jijie 淮南子鴻烈集解, Taipei: Wenshizhe.

Liu Yushu 劉玉書 (ed.) 1989, Yinshan zhengyao 飲膳正要, Beijing: Renmin weisheng chubanshe.

Lo, V. 2001, 'Huangdi Hama jing (Yellow Emperor's Toad Canon)', in Asia Major, third series, 14.2, 61-99.

Lu Qinli 逯欽立 (ed.) 1979, Tao Yuanming ji 陶淵明集, Beijing: Zhonghua.

McDermott, J. P. 2006, A Social History of the Chinese Book. Books and Literati in Late Imperial China, Hong Kong: University of Hong Kong Press.

McLaren, A. 1998, Chinese Popular Culture and Ming Chantefables, Leiden: E. J. Brill.

Ma Jixing 马继兴 2003, 'Bencao gangmu chuban de kaocha' 本草纲目出版的考察, in Qian Chaochen 钱超尘 and Wen Changlu 温长路 (eds), Li Shizhen yanjiu jicheng 李时珍硎究集 成, Beijing: Zhongyi guji chubanshe, 16-27.

Major, J. and Cook C. (eds) 1999, Defining Chu: Image and Reality in Ancient China, Honolulu: University of Hawai'i Press.

Métailié, G. 2007, 'The Representation of Plants: Engravings and Paintings', in Bray F. et al. (eds), Graphics and Text in the Production of Technical Knowledge in China: The Warp and the Weft, Leiden: E. J. Brill, 487-520.

Métailié, G. and Haudricourt A. G. 1994, 'De l'Illustration Botanique en Chine', Études chinoises, 13.1-2, 381-416.

Métailié, G. 1998, 'Un manuscrit en quête d'auteur. Du Plinius Indicus de Johan Schreck au Bencao gangmu de Li Shizhen et au Bencao Pinhui Jingyao de Liu Wentai', Journal Asiatique, 286.1, 211-33.

Nappi, C. 2006, 'The Monkey of the Inkpot: Natural History and its Transformations in Early Modern China', unpublished PhD dissertation, University of Princeton. 
Needham, J. 1986, Science and Civilization in China, Cambridge: Cambridge University Press, vol. 6, part I.

Pei Yaoqing 裴耀卿 (ed.) 2004, Si mu an ji ji yu shi 司牧安驩集語釋, Beijing: Nongye chubanshe.

Powers, M. 1991, Art and Political Expression in Early China, New Haven and London: Yale University Press.

Reiter, F. C. 1992, 'Some Remarks on the Chinese Word T'u “Chart, Plan, Design”', Oriens, 32, 308-27.

Shang Zhijun 台志钧 (ed.) 1994, Bencao tujing 本草图经, Hefei: Anhui kexue jishu chubanshe.

Sterckx, R. 2002, The Animal and the Daemon in Early China, Albany: State University of New York Press.

— 2004, 'Attitudes Towards Wildlife and the Hunt in Pre-Buddhist China', in Knight J. (ed.), Wildlife in Asia: Cultural Perspectives, London: RoutledgeCurzon, 15-35.

- 2005, 'Animal Classification in Ancient China', East Asian Science, Technology and Medicine, 23, 26-53.

— in press, 'Zoomorphism and Sacrificial Religion in Early China', in Wang E. (ed.), Zoomorphic Imagination in Chinese Visual Culture, Periscope and Isabella Stuart Gardner Museum.

Sun Yirang 孫詣讓 (ed.) 1987, Zhouli zhengyi 周禮正義, Beijing: Zhonghua.

Tang Bingzheng 湯炳正, Li Daming 李大明, Li Cheng 李誠 and Xiong Liangzhi 熊良智 (eds) 1996, Chuci jin zhu 楚辭今注, Shanghai: Shanghai guji.

Unschuld, P. 1986, Medicine in China: A History of Pharmaceutics, Berkeley: University of California Press.

2000, Medicine in China: Historical Artifacts and Images, Munich/London: Prestel.

Wang Hongbin 王鸿宾 2006, 'Tan “Erya tu” ji qi yuanzuozhe Guo Pu’ 谈 “尔雅图” 及其原作者 郭橏, Wenwu shijie, 1, 47-50/70.

Wang Jian 王剑 (ed.) 1996, Li Shizhen xueshu yanjiu 李时珍学术硏究, Beijing: Zhongyi guji chubanshe.

Wang Liqi 王利器 (ed.) 1993, Yanshi jia xun jijie 顏氏家訓集解, Beijing: Zhonghua.

Wang, M. C., Wang E., Sterckx R. and Guolong Lai 2006, A Bronze Menagerie: Mat Weights of Early China, Boston: Isabella Stewart Gardner Museum and University of Pittsburgh Press.

Wu Hung 1989, The Wu Liang Shrine: The Ideology of Early Chinese Pictorial Art, Stanford: Stanford University Press.

Wylie, A. 1901, Notes on Chinese Literature: With Introductory Remarks on the Progressive Advancement of the Art; and a List of Translations from the Chinese into Various European Languages, Shanghai: American Presbyterian Mission Press (preface 1867).

Xia Henglian 夏亨廉 and Lin Zhengtong 林正同 (eds) 1996, Handai nongye huaxiang zhuanshi 汉代农业画像砖石, Beijing: Zhongguo nongye chubanshe.

Xie Zongwan 谢宗万 1985, 'Bencao gangmu tuban de kaocha' 本草纲目图版的考察, in Zhongguo yao xuehui yaoxueshi xuehui (ed.), Li Shizhen yanjiu lunwen ji 李时珍硎究论文集, Hubei kexue jishu chubanshe, 145-99.

Xie Zongwan 谢宗万 (ed.) 2001, Bencao gangmu yaowu caise tujian 本草綱目藥物彩色圖鑒, Beijing: Renmin weisheng chubanshe.

Yang Bojun 楊伯峻 1995, Chunqiu Zuozhuan zhu 春秋左傳注, Beijing: Zhonghua.

Yang Xiaoneng 2000, Reflections of Early China: Decor, Pictographs, and Pictorial Inscriptions, Seattle and London: The Nelson-Atkins Museum of Art and University of Washington Press.

Zhao Zhongyi 趙仲邑 (ed.) 1997, Xinxu xiang zhu 新序詳詿, Beijing: Zhonghua.

Zheng Jinsheng 鄭金生 2003, 'Mingdai huajia caise bencao chatu yanjiu' 明代畫家彩色本草插 圖矿究, Xinshi xue 新史學, 14.4, 65-120.

Zhou Shirong 周世榮 1990, 'Mawangdui Han mu de “shenqi tu” bohua’ 馬王堆漢墓的“神祇 圖”帛畫, Kaogu, 10, 925-8. 